\title{
NATIONAL SYNCHROTRON LIGHT SOURCE SAFETY-ANALYSIS REPORT
}

\author{
Edited by K. Batchelor
}

July 1982

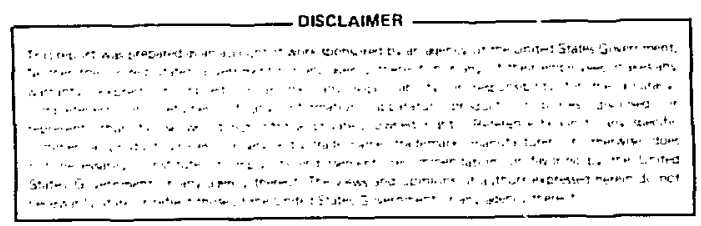

NATIONAL SYNCHROTRON LIGHT SOURCE

\author{
BROOKHAVEN NATIONAL LABORATORY \\ ASSOCIATED UNIVERSITIES, INC. \\ UPTON, LONG ISLAND, NEW YORK 11973 \\ UNDER CONTRACT NO. DE-AC02-76CH00016 WITH THE \\ UNITED STATES DEPARTMENT OF ENERGY
}




\section{DISCLAIMER}

This report was prepared as an account of work sponsored by an agency of the United States Government. Neither the United States Government nor any agency thereof, nor any of their employees, nor any of their contractors, subcontractors, or their employees, makes any warranty, express or implied, or assumes any legal liability or responsibility for the accuracy, completeness, or usefulness of any information, apparatus, product, or process disclosed, or represents that its use' would not intringe privately owned rights. Reference herein to any specific rommercial product, process, or servic, by trade name, trademark, manufacturer, or otherwise, does not necessarily constitute or imply its endorsement, recommendation, or favoring by the United States Government or any agency, contrartor or subcontractor thereof. The views and opinions of authors expressed herein do not necessarily state or reflect those of the United States Government or any agency. contractor or subcontractor thereol.

\section{Printed in the United States ol America}

Available from

National Technical Information Service

U.S. Department of Commerce

5285 Port Royal Road

Springfield, VA 22161

NTIS price codes:

Printed Copy: A07; Microfiche Copy: A01 


\begin{abstract}
This document covers all of the safety issues relating to the design and operation of the storage rings and injection system of the National Synchrotron light Srirce. The building systems for fire protection, access and egress are described together with air and other gaseous control or venting systems. Detalls of shielding against prompt bremstrahlung radiation and synchrotron radiation are described and the administrative requirements to be satisfied for operation of a beam line at the facility are given .
\end{abstract}


1. Introduction and Description of the Facility

2. Policy

2.1 Introduction

2.2 Project Safety Committee

2.3 Laboratory Safety Committee

2.4 Safety Training

3. Building System

3.1 Introduction

3.2 Building Access and Egress

3. 3 Hazards and Controls

3.3.1 Controlled Entry to the Experimental Area

3.3.2 Fire Hazard and Control

3.3.3 Occupational Health Hazards

4. Injection Systems

4.1 Introduction

4.2 Injection System Operation

4.3 Hazards and Controls

4.3.1 Radiation Hazards

4.3.2 Linac Transfer Line and Booster Shielding

4.3.3 Procedure for Securing the Linac/Booster Radiation Area

4.3.4 Electrical Safety in the Injection Systems

4.3.5 Occupational Health Hazards

4.3.6 Accident Assessment for the Injection Systems

5. VUV and $X$-ray Storage Rings

5.1 Introduction

5.2 Storage Ring Operation

5.3 Hazards and Controis

5.3.1 Radiation Hazards in the Storage Rings

5.3.2 Shielding

5.3.3 Procedures for Securing the Storage Rings

5.3.4 Electrical Safety in the Storage Rings

5.3.5 Accident Assessment for the Storage Rings

5.3.6 Occupational Health Hazards

6. Experimental Areas

6.1 Introduction

6.2 Experimental Beam Lines Operations

6.2 .1 Int roduction

6.2.2 X-ray Beam Lines

6.2.3 VUV Beam Lines

6.3 Radiation Hazards in the Experimental Areas

6.3.1 Introduction

6.3.2 Shielding

6.4 Beam Line Radiation Hazards Controls

6.4.1 Introduction

6.4.2 Beam Lines Controls

6.5 Fault Analysis of Attempted Entry to an X-ray Experimental Hutch

6.6 Occupational Health Hazards 
NSLS Safety Aralysis Report Contents

Appendix I - Procedures for Securing the Storage Rings
Appendix II - Review of Beam Line Lesigns
Appendix III - Safety Requirements for Operation of a Beam Line at NSLS
Appendix IV - Beam Line Bremsstsrahlung Shielding at the NSLS
Appendix V - Visible Light Hazard at the NSLS VUV Ring
Appendix VI - Guidelines for Beam Line Radiation Safety, NSLS 


\section{NATIONAL SYNCHROTRON LIGHT SOURCE SAFETY ANALYSIS REPORT}

\section{Introduction and Description of the Facility}

The NSLS synchrotron radiation facility includes two electron storage rings. The first one, with a maximum electron energy of $2.5 \mathrm{GeV}$, is princtpally intended for generation of the radiation spectrum of $0.5 \AA$ to $100 \AA$. The second ring, with a maximum energy of $0.7 \mathrm{GeV}$, will provide for the wavelength region of about $10 \AA$ to $1000 \AA$ and above.

As there is considerable interest in utilization of the wavelength domain below $1 \AA$, beam "wigglers" will be incorporated in the X-ray ring structure, making use of $6 \mathrm{~T}$ peak field superconducting multipole magnets. This will extend the available spectrum effectively down to $0.1 \AA$ (hv $\leq 100$ $\mathrm{keV})$, as is indirated in Figure 1, where the photon flux per mrad of arc and per cent of $(\Delta \lambda / \lambda)$ is given versus wavelength for the NSLS design parameters. In addition to the use of high field wigglers, the option of operating the $\mathrm{X}$-ray storage $\mathrm{ring}$ at higher than the $2.5 \mathrm{GeV}$ design energy is kept in focus so that with minimal additional cost, at a later stage, the maximum energy of the $\mathrm{X}$-ray ring could be increased.

Initially, one beam wiggler will be incorporated, although the X-ray lattice structure will accommodate up to 5 units. For the VUV ring, similarly, beam undulators will be incorporated. However, in this case, there is no particular objective of making available a shorter wavelength domain, which is readily available from the $X$-ray ring; rather, in this case, modest field, many pole, coherent undulators are planned to achieve selected wavelength photon flux enhancements by several orders of magnitude. The VUV ring will provide for 16 primary beam ports $(14$ arc sources, 2 undulator ports) whereas with the X-ray ring 28 primary ports are avallable, including up to 5 wiggler ports. 


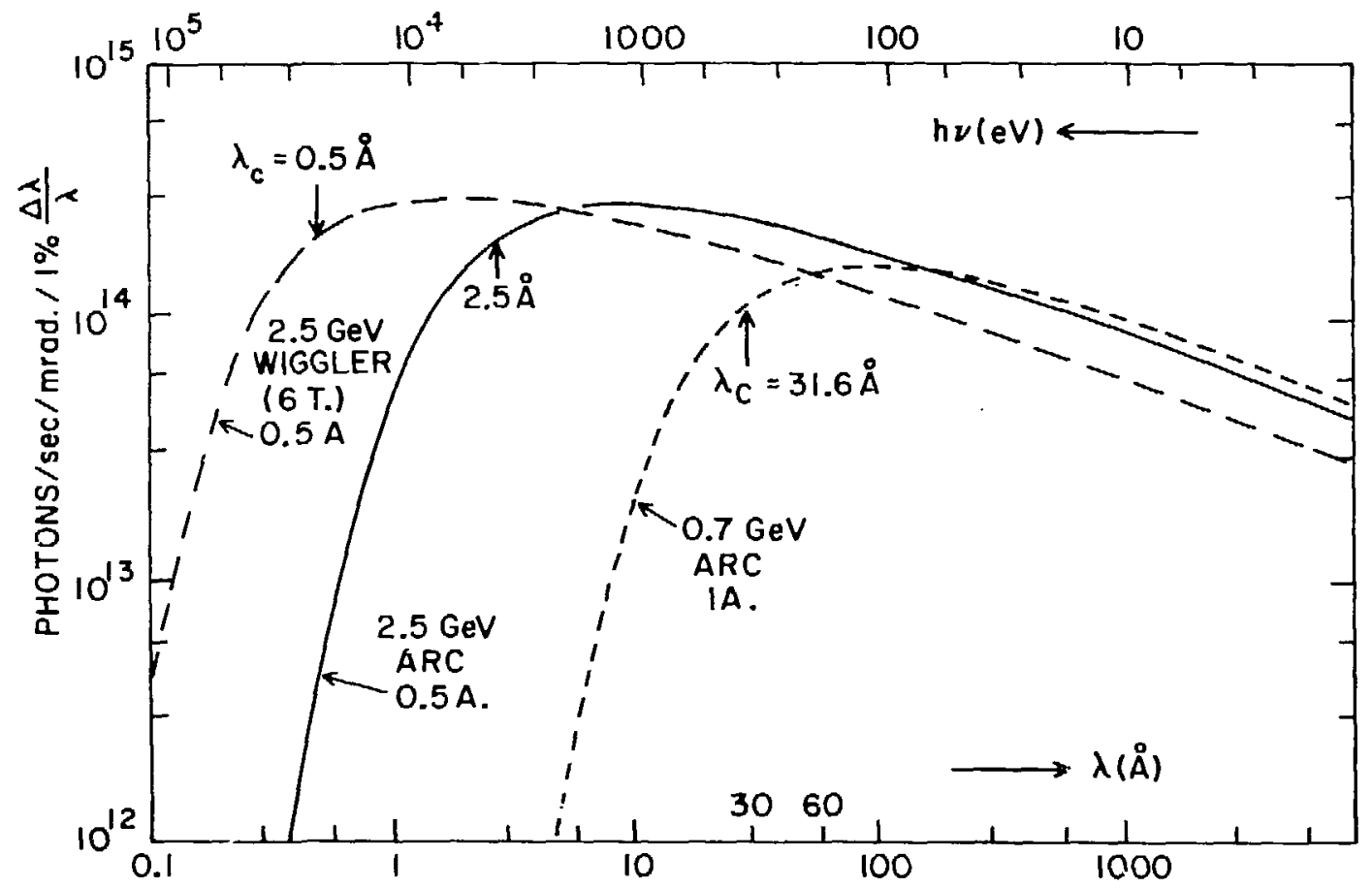

Figure 1. Synchrotron radiation spectra for the NSLS design parameters. 
The general arrangement of the principal elements of the synchrotron radiation facility is shown in Fig. 2. Electrons, originating from a hot cathode diode gun driven by a $110 \mathrm{kV}$ pulsed modulator are accelerated in an s-band linear accelerator to $70 \mathrm{MeV}$, injected into a booster synchrotron and accelerated to $700 \mathrm{MeV}$. After allowing the beam to "damp" at maximum energy in the booster, the beam is transferred either to the VUV or the $\mathrm{X}$-ray storage ring. By repeating this process, the charge magnitude is built up in the storage rings to the design current value. In the case of the $X$-ra. ring, the stored charge is then further raised in energy by acceleration to $2.5 \mathrm{GeV}$, with a 0.5 amp stored beam current.

The experimental beam lines are situated in such a location that they are tangential to the electron orbit in the dipole or wiggler magnetic field regions of the storage rings. Thus synchrotron radiation generated when the relativistic electrons are bent by these magnetic fields emerges down these beam ports and into a series of individual beam lines where the radiation is used for experimental purposes. In the Vacuum Ultra-Violet Storage Ring the photon beam remains in a vacuum all the way to the experimental chamber whereas in the $\mathrm{X}$-ray Storage Ring the photon beam may in some experiments pass through a beryllium window into air before reaching the experimental chamber.

2. Policy

2.1 Introduction. From a management viewpoint, safety is represented at the highest level in the National Synchrotrc: Light Source Division. From looking at the Division Organization chart (Figure 3), it can be seen that the Division Safety Coordinator, K. Batchelor, also serves as the Section Head for the Accelerator/Storage Ring part of the facility. 


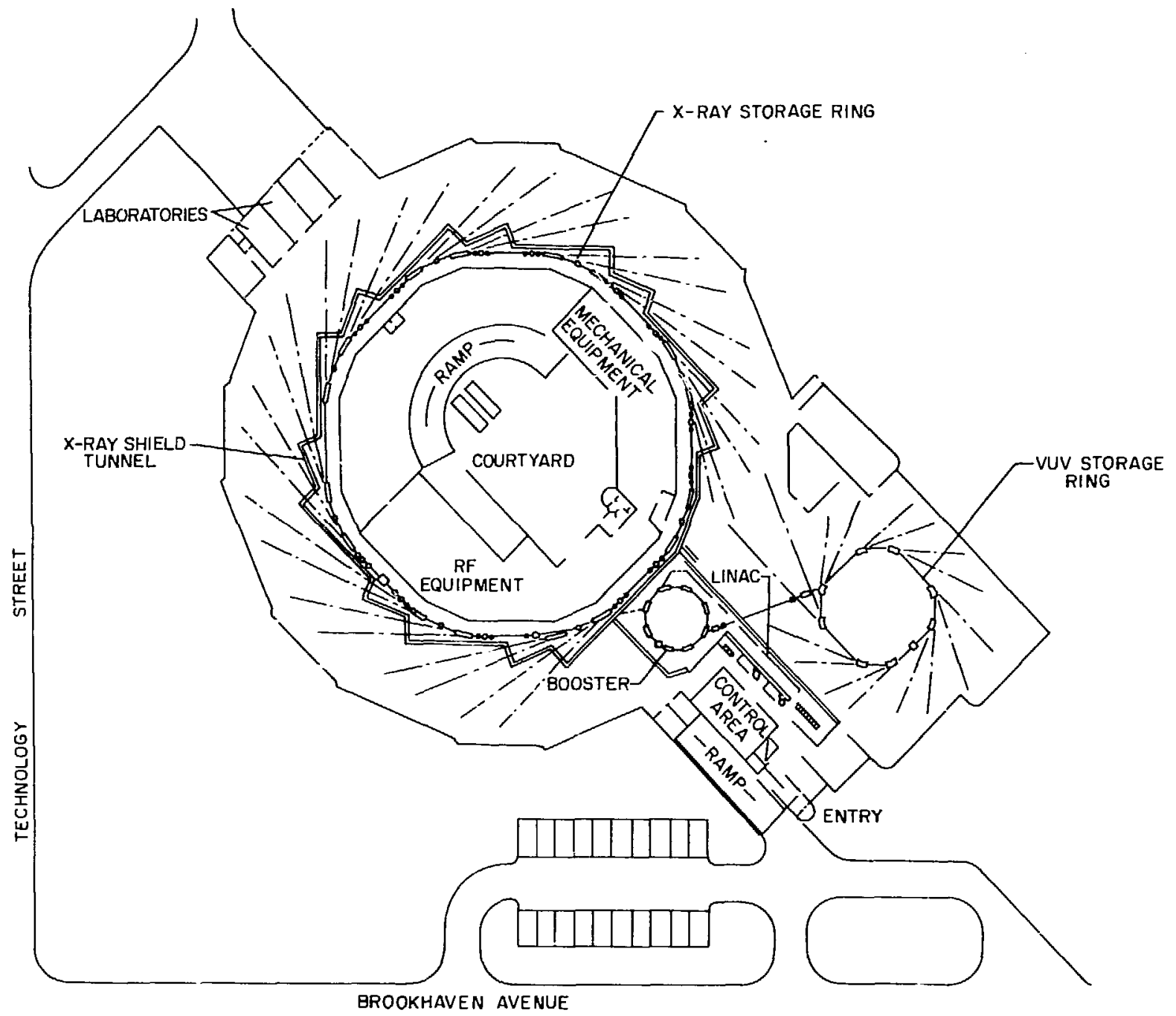

Figure 2. Building layout of the NSLS. 


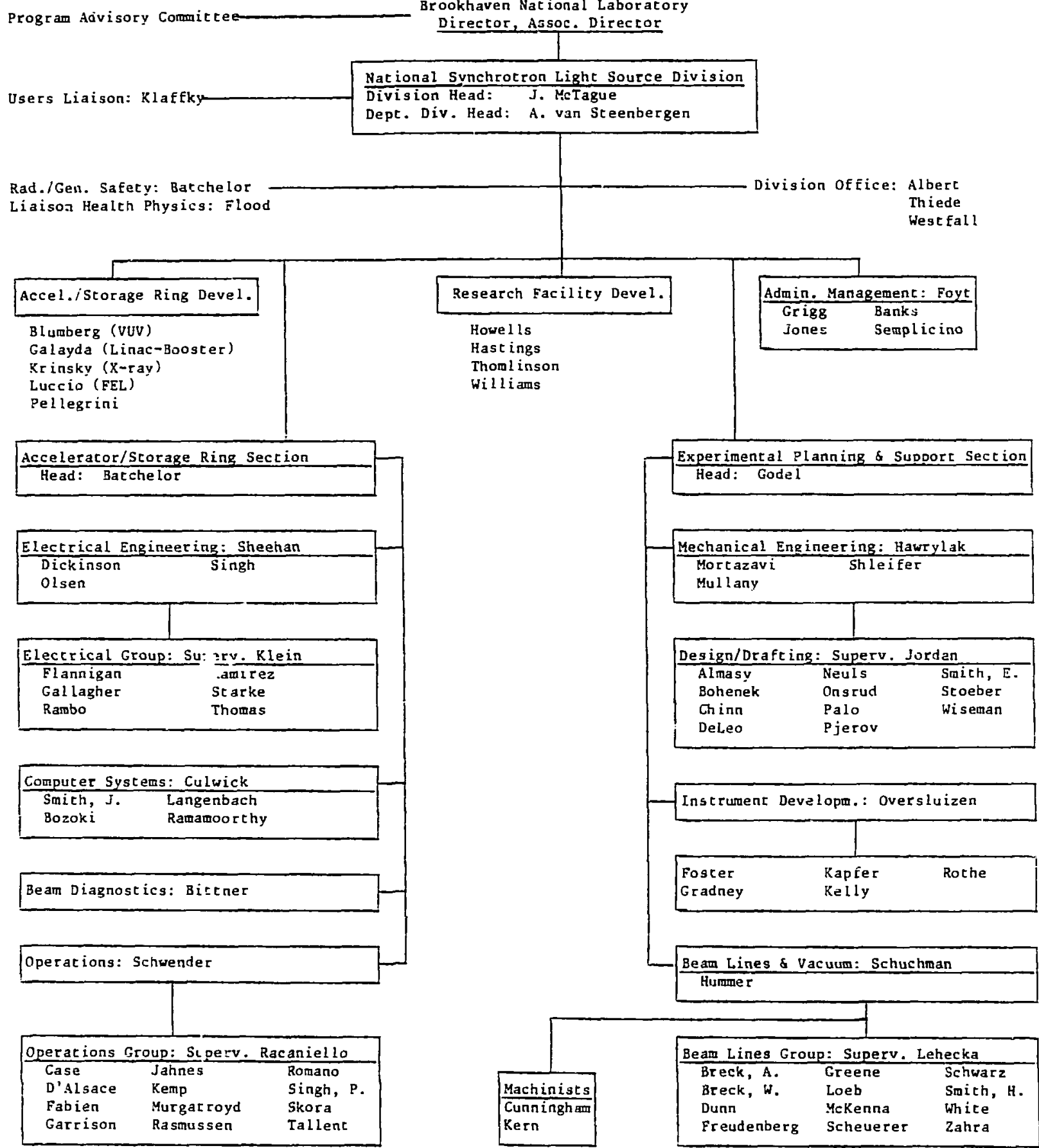

Figure 3. NSLS organization chart. 
A member of the Safety and Environmental Protection Division, name1y

c. Flood, works in liaison with the Division on safety related matters.

2.2 Project Safety Committee. There is a Project Safety Committee which reviews all phases of the project when they are at the design stage and makes recommendations in regard to safety matters. This committee is made up of the following people.

K. Batchelor - NSLS Division Safety Coordinator

C. Flood (ex officio) - Safety and Environmental Protection Division

T. Oversluizen - Instrument Development Engineer, NSLS

G. Schwender - Operations Engineer, NSLS

W. Thomlinson - Physicist, NSLS Experimental Group

G. Williams - Physicist, NSLS Experimental Group

R. Zantopp - Health Physicist, Safety and Environmental Protection Division

This committee, having reviewed the policies regarding experimental use of the facility, will be responsible for reviewing each experimental station before it becomes part of the operating facility. Any major modification requirer a further review. It will have final jurisdiction over the operation of all beam lines in regard to operational safety. (See Memorandum setting up committee.)

2.3 Laboratory Safety Committee. Whenever changes not. covered by this document or requiring a new S.A.R. are made by the Division Safety Committee they are brought to the Laboratory Safety Committee for their review and approval. The policies are not implemented until such a review has taken place and approval has been obtained. In addition to the Latoratory Safety Committee Reviews, members of the Safety and Environmental Protection Division act as advisors to the Division in any safety matters. The Safety and Environmental Protection Division Representative assists the Division in the implementation of the Laboratory Safety Program and also assists in training NSLS personnel in safety matters. 


\section{BROOKHAVEN NATIONAL LABORATORY \\ MEMORANDUM}

$\begin{array}{ll}\text { DATE: } & \text { April 27, } 1982 \\ \text { TO: } & \text { NSLS Personnel } \\ \text { FROM: } & \text { J. P. MeTague } \\ \text { SUBJECT: } & \text { Safety Responsibilities }\end{array}$

Part of the responsibility of any Division of the Laboratory is the provision of a direct 1 na of responsibility in regard to safety in that division. A. van Steenbergen, in a memo dated December 7, 1981, set up the NSLS Safety Committee to review all new designs with regard to safety and make recommendations to tue Project management in this regard. I now wish to endorse this Committee as the Division Safety Committee and confirm the appointment of the Committee Chairman, K. Batchelor, as the Division Safety Coordinator. He will report directly to me on safety matters. The other members of the Commlttee are T. Oversluizen, G. Schwender, W. Thomlinson, G. Williams and R. Zantopp. C. Flood, as liaison between Safety and Environmental Protaction Division and the NSLS Division will serve as an ex officio member of the NSLS Division Safety Committee. 
2.4 Safety Training. In many training areas such as, for example, respirator training, safe crane operation, or materials handling, the training is given by the regularly scheduled Safety and Environmental Protection Division Programs. However, there are a number of topics peculiarly related to the NSLS Eacility where Division safety training is necessary. These items are generally related to electrical safety or radiation safety areas. Written procedures for securing radiation areas or for operating high voltage equipment are provided and project operating staff are trained in the 1mpiementation of these procedures. Detailed procedures are given below.

Experimental beam line users will undergo a special training program operated by both NSLS staff and Safety and Environmental Division staff before qualifying to operate the beam line. This program will focus particularly on radiation safety and hutch entry controls but will also address other safety matters related to beam line operation.

\subsubsection{Responsibility and Training of NSLS Operators}

2.4.1.1 Training. Before becoming a qualified operator of the NSLS facility, each candidate must have received machine operation training. This instruction phase will include safety related issues which will be under the supervision of the Safety Coordinator. These instructions will include training in $\bar{i}$ ire protection and control; electrical safety procedures; chenfcal handling and control; and radiation safety procedures, all of which will be documented and avas.lable for new operators.

2.4.1.2 Responsibilities. On each shift at least two qualified operators will be on duty and will have the responsibility for the operation of the NSLS facility. A third person will be available on call at all times to ensure that the control room is always manned. A designated operator 
will have the responsibility that all safety procedures are being strictly adhered tu. In matters of machine operation or safety, their word is final. If necessary, they have the duty to shut down any part of the facility be it the entire inachine or a local beam line.

Their daily duties are as follows:

1. Operation of the facility.

2. Searching and securing areas of the building that are to be subject to radiation.

3. Strictly enforcing all sifety procedures.

4. During each tour oc duty a physical safety inspection must be made and logged. Items included in the $\log$ will be related to machine operation and the operation of each beam line. For example:

Machine: Runving conditions and safety related problems.

Beam Line: a. Mode of operat:on.

b. Names of personnel working on the beam line.

c. Safety related problems.

d. Time of inspection, etc.

During this safety tour hutches that are open should be entered and inspected to observe that compliance with hutch safety procedures are being met. Hutches not open will be visually inspected via a viewing port.

5. Operatcis will monitor hutches via TV monitors at random times to assure that safety procedures are being adhered to.

\subsubsection{Personnel Security Systems}

2.4.2.1 Testing Procedure. The linac tunnel - booster ring, $\mathrm{X}$-ray tunvel, and the inner circle of the VuV are subject to radiation and a system for clearing all personnel and securing these areas has been implemented and described in Sections 4.3.3 and 5.3.3. In the future a 
microprocessor will collect status information from the three systems and provide the machine operator with a current display of the entire building's safety system.

Each system is made up of hard wired relay logic in a fail safe configuration. Therefore, detailed circuit checking of the interaction of each emergency stop button and door sensors for the desired safety response on shutters and power supplies will be carried out at least once each six month period.

The dates and results of these tests will be logged in the security operation $\log$ book. This $\log$ will also include any safety related items associated with the security system on a daily basis and will be under the supervision of the Safety Coordinator.

\section{Building Systems}

3.1 Introduction. The building systems, such as air conditioning, waterand compressed air, or nitrogen, are primarily designud to serve the machine equipment and to provide for sprinklers or ald evacuation as regards the building safety program. It can be seen in Figure 2 that the $\mathrm{X}$-ray storage ring is housed in a tunnel with beam lines extending through the tunnel wall into the X-ray experimental area and with mecherical and electrical equipment housed in buildings inside the $X$-ray ring tunnel. The vUV storage ring, Control Room, Linear Accelerator, and Booster are located in an attached wing at the same lower floor level as the $\mathrm{X}$-ray ring and Experimental area. A group of laboratories connect to the $X$-ray ring end a single laboratory is situated at the conjunction of the VUV and X-ray experimental floors at this same level which is approximately $5 \mathrm{ft}$ below grade. Offices and a computer room are situated on an uper level above the control room and Linac/Booster equipment areas. Flans are underway for a building off the inner courtyard which will house the cryogenic system of a superconducting wiggler in the $X$-ray ring. 
3.2 Building Access and Esress. Normal access to the building will be the main entrance situated off Brookhaven Avenue (see Fig. 4). From this point, personnel can go freely to the upper level or to the experimental floor with access to the experimental floors being under key control. The only other free access areas are the electrical and mechanical equipment rooms situated off the inner courtyard which may be reached via a ramp through a cut in the bullding. Protective barriers have been provided adjacent to the door which exits to the base of the ramps so that personnel cannot walk into traffic on the roadway. There is an escape ladder from the inner courtyard area which allows personnel to pass over the $\mathrm{X}$-ray experimental roof in the event that fire blocks the ramp exit. There are two Exits from the $X$-ray tunnel area, one to the Inner courtyard area and one to the $r f$ equipment area and thence the inner courtyard or the second floor office area. The two exits are separated by half of the ring circumference or approximately 270 feet, so that the maximum distance from an exit is about 135 feet. The maximum allowable travel distance allowed by BNL OHS Guide 4.1.2 "Means of Egress" in unsprinklered areas is 100 feet. However, given the limited and controlled access to the $X$-ray ring tunnel, the lack of combustible materials within the enclosure which would provide a rapidly developing fire, and the provision of closely spacel smoke detectors designed to provide early warning to occupants, no undue personnel hazards are presented by the $135 \mathrm{ft}$ egress distance. The two exits from the VUV experimental area are diammetrically opposite each other, one near the main entrance and lobby area and one on the X-ray experimental floor near the VuV laboratory. The maximum travei distance to an exit from any point in the VUV experimental area is approximately 200 feet which is also true of the 


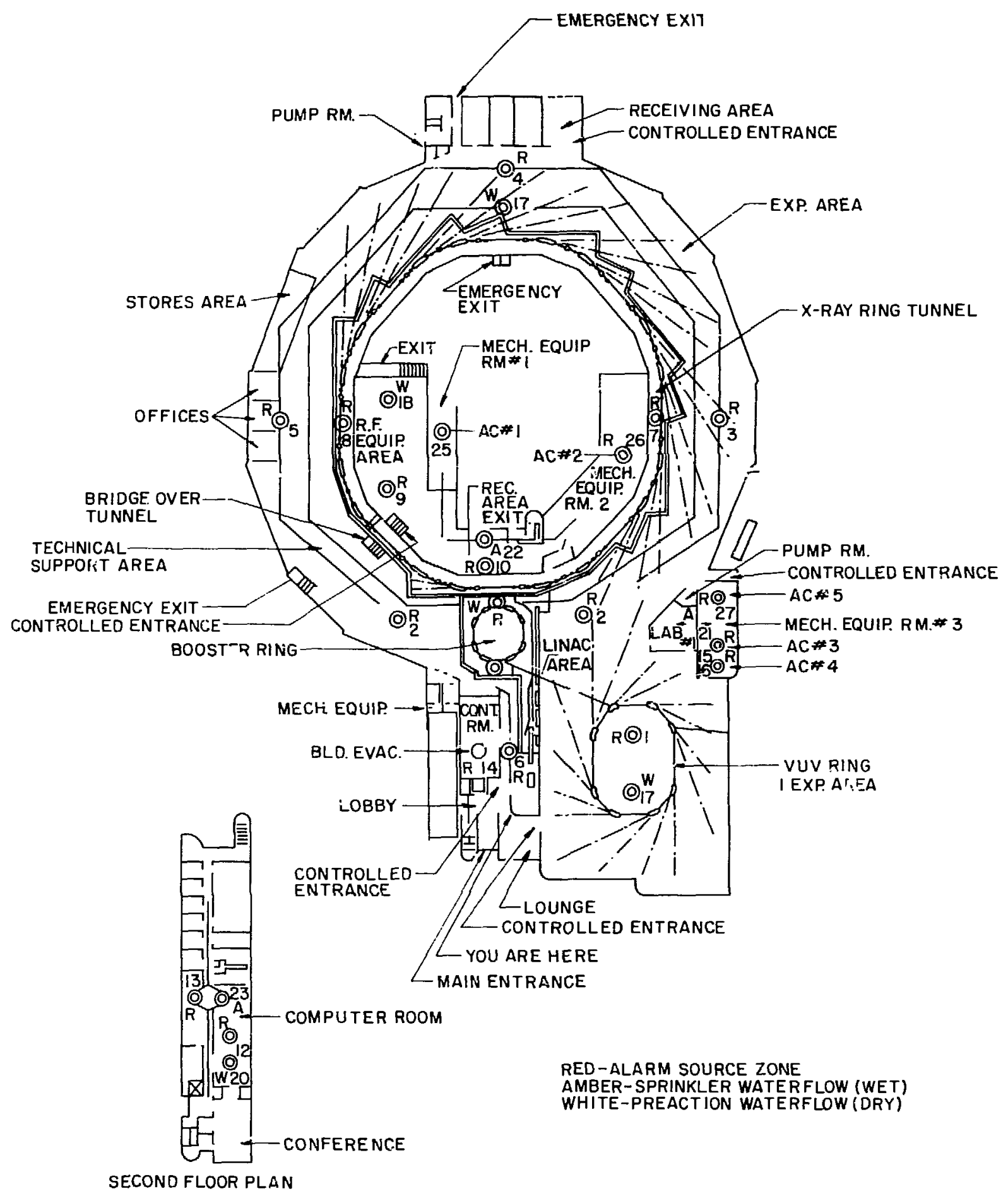

Figure 4. Plan showing fire protection systems. 
$x$-ray experimental floor. The maximum allowable travel distance allowed by BNL OHS Guide 4.l.2 in sprinklered areas is 150 feet. However, given the limited and controlled access to the VUV experimental area and X-ray experimental floor, the largely visually open areas which -nable occupants to prompty evaluate the threats from developing fires, and the provision of smoke detecto:s designed to provide early warning to occupants, no undue personnel hazards are presented by the $200 \mathrm{ft}$ egress distance. Two exits are provided from the Lina: Booster enclosed area, one to the X-ray experimental floor and the other to the lobby area near the main entrance. Except where indicated above, the egress design for the building satisfies the requirements of BNL OHS Guide 4.1.2.

\subsection{Hazards and Controls}

3.3.1 Controlled Entry to the Experimental Areas. Since both the $X$-ray and TUV experimental areas are considered potential radiation areas, film badges are required for all personnel entering these areas. All entry points to these areas are controlled by utilization of a key attached to each authorized users film badge. Visitors will be given a temporary film badge and accompanied by an authorized user whenever they enter these areas.

3.3.2 Fire Hazard and Control. The Light Source facility relies on several different methods of fire protection. These include portable fire extinguishers, combined sprinkler and fire standpipe system, smoke and heat detectors, fire area separation, manual fire alarm stations, and an annunciator and signal system that is tied into the Site Protective Signaling System.

Approximately 25 portable Halon 1211 fire extinugishers (UR rated $3 \mathrm{~A}: 80 \mathrm{BC}$ ) are located throughout the building. The maximum travel distance to a fire extinguisher is approximately 75 feet. 
Fire separation is achieved between the experimental areas and the administrative space by sprayed fireproofing material on the steel and automatically activated steel fire curtains that provide a 2 hour rating. The computer room is also separated from the administrative area by 2 hour fire rated partitions.

A sprinkler system is provided throughout the facility with the exception of the $\mathrm{X}$-ray tunnel and the Linac tunnel areas. These shielded areas only have smoke and thermal detectors. There are two types of sprinkler systems installed, one is a preaction type which requires sensing of smoke by a smoke detector to fill the normally dry system with water ready For action should a sprinkler head fuse ultimately melt, the other is direct action whereby the wacer is always present in the pipes and melting of a fuse activates the sprinkler. The sprinkler system, is installed, consists of four pieaction sprinkler zones and a wet sprinkler zone. The four preaction zones cover the following areas: One zone for the VUV area including the Linac, Control Room, Lobby, Lourge and the Tollet Rooms near the Booster power supplies on the first floor. One zone for the $x$-ray experimenial areas inciuding Laboratories 2, 3 and 4, the Receiving axea and Toilet Rooms adjacent to the labs. One zone for the $R F$ equipment room area, and the fourth zone for the Computer area.

The wet sprinkler zone covers the second floor office spaces, Mechanical Equipment Rooms 1, 2 and 3, Laboratory number 1, the Receiving area from the courtyard and the fire hose cabinets (standpipe system).

The standpipe system is enclosed in recessed wall cabinets located throughout the experinental and administrative areas including the stairwells. The cabinets contain a portable fire extinguisher and a hose valve for connection of the fire department's fire hose. 
In the wet sprinkler system, the sprinkler heads are attached to the piplng system which contains water under pressure at all times. When the sprinkler heads sense a temperature sufficientiy high $\left(212^{\circ} \mathrm{F}\right.$ for exposed heads and $165^{\circ} \mathrm{F}$ for concealed heads) so that the link fuses, water will discharge.

There are no smoke or thermal detectors in areas protected by the wet sprinkler system, except for the seminar room and lobby. These two spaces have smoke detectors that activate the steel fire shutters to close and isolate the experimental areas from the administrative area.

In the pre-action areas, there is a pattern of smoke detectors alternating between ionization type and photoelectric types. The seusing of smoke by a detector will activate the pre-action system and release water into the sprinkler piping. The water will remain in the piping until the Euse of the sprirkler head melts, as with a conventional wet system, thus opening the head and discharging water. In some locations, such as toilets, heat detectors are used in lieu of smoke detectors.

In addition to the autonatic systems described above, there are manual fire alarm stations within the preaction zones. Activation of the manual fire alarin station in any zone, will allow water to enter and fill the sprinkler piping of its respective zone. Activation of a manual emergency release (MER) valve, located at each sprinkler station, will also result in water filling in its respective piping zone. Consequently, operation of the fire detection system alone or manual fire alarm station alone, or manual emergency release alone, or fusing of a sprinkler head alone will not result in the discharge of water. 
The activation of any detector or manual fire alarm station in the pre-action systems will energize a solenoid valve which will allow water to fill the sprinkler piping and will also energize an audible alarm. The fusing of a sprinkler head in the wet pipe system, which permits water to discharge, will also sound the fire alarm system. Alarms are sounded locally and at tine Fire Alarm Control Panel.

The pre-action sprinkler syster is supervised by pressurized air. Damage to a sprinkler head or sprinkler piping will result in the loss of supervisory pressure. This drop in pressure will send a signal to the BNL fire and rescue group. A local trouble bell also sounds at the sprinkler station.

Five zones have been established for the distribution of conditioned air in the facility. These include one zone for the Administrative area, one zone for the VUV area, one zone for the Linac area, one zone for the south ha1f of the X-ray experimental area and tunnel, and the fifth zone for the north half of the $X$-ray experimental area and tunnel. The supply and return air ducts from these areas have ionization type smoke detectors installed. When the units detect the presence of smoke they will sound a fire alarm. They will also cause the fans to shut down and the smoke dampers to close off the respective zone, preventing air circulation.

Additionally, the fans in any zone can be manually shut down from a HVAC control panel in the telephone closet. A master fan shut down switch which will shut down all fans is conveniently located in the main entrance lobby.

Continuously ringing fire alarm bells are used to alert building occupants once a fire alarm signal is initiated. Intermittent ringing of 
the fire alarm bells, to notify building occupants to evacuate the building, is initiated by a manually operated alarm in the Control Room.

To shorten the Fire Department's time in lacating a fire in the building, the entire alarm detection system 1s subdivided into 32 zones. Upon activation of any detector or sr $:$ nl:ier waterflow, all alarm signalling units will sound continuonsiy, and the respective zone alarm lamps will light on the Fire Aiarm Control Panel and the Annunciator Panel.

For purposes of operation and maintenance, whenever any of the elements of the fire protection system are not operable or the system is not in its normal operating mode, a visual and audible signal will result at the Fire Alarm Control Panel.

All the alarm and detection systems operate off the normal building power supply. However, the system has an automatic emergency battery supply that will operate for a period of 24 hours, if normal power is interrupted. Future plans, include connecting the fire alarm system to the building's emergency generator power supply. The emergency generator is housed in building 535 and will be electrically connected to building 725 .

The National Synchrotron Light Snurce facillty will be the first building on site to utilize a Data Gathering Panel for fire protection. The panel is the interface between the Local Protective Signaling System and the Site Protective Signaling System. Local alarm and supervisory circuits from the Fire Alarm Control Panel are fed into the Data Gathering Panel which is tied through 2 pairs of telephone lines to Police Headquarters, Building 50. A control unit in Building 50, which receives the signals, interprets the status of the local alarm (pre-action, fire, trouble, etc.) and then transmits this information to the firehouse for appropriate action. 


\subsubsection{Occupational Health Hazards}

The hazards associated with this facility are no different from those encountered in any research laboratory building.

3.3.3.1 Toxic Hazards. Any of the laboratories adjacent to the experimental floor of the X-ray and VUV rings could ultimately be used for target preparation and as such may involve the use of toxic materials. All experimenters using the facility are required to give a list of substances involved in their experiment for review of the NSLS Safety Committee prioz to approval of their experiment for operation. Fume hoods and exhaust systems are provided in the laboratories.

3.3.3.2 Laser Hazards. Conventional laser systems will be in common use for alignment purposes in one or more of the NSLS laboratories. These systems are subject to the BNL controls described in the BNL safety manual section 2.3 .1 .

\subsubsection{Cryogenic Hazards. iSubstantial quantities of heliun} will be used for the cryogenic wiggler magnet for the $X-r a y$ ring. A helium refrigerator dewar and gas circulation system will be part of this equipment. The cryogenic house in the $x$-ray ring courtyard area will contain this equipment. The house will have a low occupancy level and there will be remote monitoring and alarms of oxygen levels, etc. Hazards are the normal ones associated with such systems such as severe cold burns, asphyxiation and over pressure.

Prior to construction the facility design will be reviewed by the Cryogenic Safety Committee.

3.3.3.4 Radiation Hazards. Throughout the NSLS facility there will exist various types of radiation hazards, resulting from electron 
losses or the usable synchrotron radiation emerging from the handing magnets in the starage rings. Other sections of this report will address these hazards in detall.

3.3.3.5 High Pressure Systems. A compressed gas system which actuates Granville-Phillips Co. gate valves is inslalled to protect ring vacuum at each experimental beam port. The system utilizes nitrogen cylinders, at approximately 2,000 pounds per square inch pressure, connected to a manifold on the X-ray ring floor near column DF4.2 where it is reduced for distribution to approximately 700 pounds per square inch.

The nitrogen is transferred to the $\mathrm{X}$-ray ring via $1^{\prime \prime}$ schedule 10S pipe, stainless steel 304. The individual lengths of piping are connected by butt welded joints. At various points around the ring there are junctions points each of which has connected to it a Bonney Forge stainless steel "weldolet" followed by an approximately 3,000 pound per square inch rated brass ball valve. This then terminates at the Granville Phillips gate valve system.

Similarly, nitrogen is transferred to the VUV ring, via $1 / 2$ " diameter $\mathrm{x} .035^{\prime \prime}$ wall thickness stainless steel 304 tubing. The tubing lengths are connected by Parker-Heanifin Corp. CPI Compression fitting unions.

The calculated stresses in both the piping and tubing are well below allowable stresses given in the tables in ANSI B31.1. Ali fittings are rated above the working pressure and both sections were tested in accordance with ANSI B341.1. The cylinder to manifold connections aro fitted with CGA connections 580 which comply with Compressed Gas Association Standard CGA $\mathrm{V}-1$. The piping and tubing are identified in accordance with BNL Safety Manual Occupational Health and Safety Guide No. 1.14.0, 
Identification of Piping Systems. The relief devices and the system are consistent with BNL Safety Manual, Occupational Health and Safety Guide No. 1.4.1, Prossurized Systems for Experimental Use.

\section{Injection Systems}

4.1 Introduction. The primary function of the Injection System is to provide $700 \mathrm{MeV}$ electrons for injection into the VUV and X-ray storage rings. The system comprises a $70 \mathrm{MeV}$ injector linear accelerator, a $700 \mathrm{MeV}$ hybrid combined and separated function electron synchrotron and two beam transport lines to transpor: Booster beams to the two storage rings at different times.

4.2 Injection System Operation. The basic source of electrons is an electron gun which will operate at a peak beam current of $100 \mathrm{~mA}$ for a 3 usec maximum pulse length at a rate of 1 pulse/sec and an energy of 110 $\mathrm{keV}$. The beam is modulated by a radiofrequency prebuncher to give an injection efficiency of about $70 \%$. A pulsed beam deflector is used to reduce the pulse width from the gun to between $0.5 \mathrm{\mu sec}$ and 1 usec. This process reduces the beam current at the input of the first accelerator guide to about $60 \mathrm{~mA}$. The surplus beam is lost on water cooled collimators in the transport line between the gun and the first accelerating guide. It is possible to stop the remaining beam on a beam stop or faraday cup beam current monitor. The rf drive system is interlocked so that entry to the accelerator enclosure will inhibit power to the klystrons powering the two accelerators. A vacuum valve beam stop in the gun-to-linac transport system is also interlocked to the entry door.

The linac will accelerate $50 \%$ to $80 \%$ of the injected beam to the full linac energy of $70 \mathrm{MeV}$. Although, In principle, the present linac is capable of accelerating more than $40 \mathrm{~mA}$ peak current to $70 \mathrm{MeV}$, more rf power 
than the $20 \mathrm{MW}$ peak which is available from each klystron is requi red in order to achieve that output energy at higher currents.

The $70 \mathrm{MeV}$ beam from the linac, after suitable shaping and scraping in a shielded area where approximately one half of the linac beam is lost, is inflected int. the booster and captured by the booster $r f$ system. The inflection system involves a pulsed septum magnet and two pulsed injection magnets to corroct the early Booster turns of circulating beam. Only about 10 to $20 \%$ of the linac beam will be captured in "betatron" phase space and accelerated by the radiofrequency system. The $r f$ power increases in amplitude with the increase of dipole and quadrupole magnetic fields which is necessary in order to achieve acceleration to th: $700 \mathrm{MeV}$ output energy of the Booster.

After acceleration the $700 \mathrm{MeV}$ beam is deflected from the stable Booster orbit into an extraction line to one or other of the two storage rings. Each of the two beam transport lines contains a shielded beam stop situated within the Linac/Booster enclosure so that beam operation of the total injection system is possible independent of storage ring operation.

\subsection{Hazards and Controls}

4.3.1 Radiation Hazards. Radiation hazards in the Injection System result from capture losses in the Linear Accelerator and Booster, and beam losses due to equipment malfunctions. The electron beam loss will result in bremstrahlung and neutron production which requires lead and concrete shielding in order to protect personnel from the radiation produced. The electron losses in the Injection System occur primarily at $70 \mathrm{MeV}$ energy or lower, are quite intense, and repeat at the 1 sec. cycle rate of the system. Normal operational losses for each acceleration cycle occur in the following places at the maximum energy and charge levels given below: 
(a) At the Input to the first Linac accelerator guide; $6 \times 10^{11}$ electrons of $<5 \mathrm{MeV}$ energy.

(b) Between accelerator guides 1 and 2; $10^{11}$ electrons of $35 \mathrm{MeV}$ energy .

(c) In the Linac/Booster transport line momentum selection region; $5 \times 10^{11}$ electrons at $70 \mathrm{MeV}$ energy.

(d) During the capture process in the Booster; $2.5 \times 10^{11}$ electrons at $70 \mathrm{MeV}$ energy.

(e) During the Booster acceleration processes; $0.5 \times 10^{10}$ electrons at $>70 \mathrm{MeV}$ energy.

(f) During the extraction process; $0.5 \times 10^{1 \mathrm{U}}$ electrons at $700 \mathrm{MeV}$ energy .

Thus, each acceleration cycle, on 1 y about $4.0 \times 10^{10}$ electrons are accelerated In the Boosier and extracted and transported down one or other of the beam transport lines to the storage rings.

Fault conditions can result in all of the Linac or Booster beam being lost at a single point any time during their acceleration cycle. Thus the maximum Linac loss may be as high as $8 \times 10^{11}$ electrons per sec at an energy of $70 \mathrm{MeV}$ and the maximum Booster loss could be $4.5 \times 10^{10}$ electrons $/ \mathrm{sec}$ at up to $700 \mathrm{MeV}$ energy.

4.3.2 Linac, Transfer Line and Booster Shielding. Here we are, concerned with the problem of shielding to attenuate radiation produced either by the steady loss or catastrophic loss of electrons from the Linac booster and Transfer lines. The shielding recommended is designed to stop electrons and the resulting bremsstrahlung in lead and then to absorb the neutrons thus produced in concrete. We w111 estimate the shielding required for injection system operations. 
Let us assume that Linac testing and allgnment operations will be carried on equivalent to 8 hours per month at 100 milliamp with $3 \mu$ sulses, 1 per second, $70 \mathrm{MeV}$. Using the loss data at $>5 \mathrm{MeV}$ given previously in Section 4.3.1 this amounts to $1.6 \times 10^{18}$ electron-MeV/month. Actual storage ring injection losses should be comparable, if the capture and acceleration process results in the losses detailed previously, charging each ring to amp 100 times per month would result in losses of $1.8 \times 10^{18}$ electron-MeV/ month in the cave around the momentum defining slit. Also, with the same total number of Booster pulses, i.e. $5 \times 10^{4} /$ month the Booster losses at 700 MeV energy total $1.8 \times 10^{17}$ electron-MeV/month. Hence the total loss in the momentum defining slit region from Linac testing and Booster operation together is $3.4 \times 10^{18}$ electron-MeV/month. The total losses in the rest of the Booster region add up to $1.1 \times 10^{13}$ electron-MeV/month.

Non-normal losses due to component failure or malfunction can occur at any time in either the Linac or Booster Synchrotron. However, since radiation loss monitors and bean current transformers are available at all times for beam intensity and loss measurements, the operators are quickly aware of a fault situation. Furthermore, any machine component which becomes out of tolerance is immediately flagged by a computer generated error program which also alerts the operacor to the problem and the region of the machine in which it occurs. We can assume that the operator will not require more than a few minutes of beam operation under loss conditions to locate a specific problem. If we conservatively assume an average of 15 minutes per week of such maximal current loss in both the Linac and Booster areas of operation, this would add losses of $2 \times 10^{17}$ electron-MeV/month to the Li nac toial and $1.2 \times 10^{17}$ electron-MeV/month to the Booster total. Both of these values lie 
within the error tolerance of the normal operational losses given earlier and may therefore be neglected.

The neutron yield, per unit beam power, malnly giant resonance neutrons, is nearly indepertent of electron energy and is taken from the calculations of W. P. Swanson (Health Phys. 37 (1979) 347-358) as $21 \times 10^{12}$ seutrons/ kjoule. The neutron fluence at a distance of $4 \mathrm{~m}$ from a point source is then

For the Booster

$$
\begin{aligned}
\emptyset & =\frac{1.1 \times 10^{18} \frac{\mathrm{MeV}}{\text { month }} \frac{12 \text { month }}{\text { year }} 2.1 \times 10^{12} \frac{\text { neut }}{\mathrm{kjoule}} 1.6 \times 10^{-16} \mathrm{kjoule} / \mathrm{MeV}}{4 \pi(400 \mathrm{~cm})^{2}} \\
& =2.2 \times 10^{9} \text { neut } / \mathrm{cm}^{2} \text { year }
\end{aligned}
$$

For the Linac cave

$$
=6.8 \times 10^{9} \text { neut } / \mathrm{cm}^{2} \text { year }
$$

The fluence to dose conversion factor is taken from NCRP5l App F8 which shows the attenuation by $(\gamma, f n)$ reaction neutrons from uranium. The dose equivalent with no concrete shielding for the entire Linac Booster area would be about $350 \mathrm{rem} / \mathrm{year}$. We assume that the dose equivalent to nonradiation workers on the second floor above this area should be maintalned below $100 \mathrm{mrem} / \mathrm{year}$. To reach this value the conversion factor of $1.5 \times 10^{-11}$ $\mathrm{rem} / \mathrm{cm}^{2}$ must be applied to the fluence for the Linac cave region and a factor of $5 \times 10^{-11} \mathrm{rem} / \mathrm{cm}^{2}$ applied to the Booster area. This gives a value of $230 \mathrm{~g} / \mathrm{cm}^{2}$ or $100 \mathrm{~cm}$ of concrete for the cave area and $190 \mathrm{~g} / \mathrm{cm}^{2}$ or $85 \mathrm{~cm}$ of concrat 3 elsewhere. The concrete shielding provided above the Linac and Linac cave area meets these requirements. There is a substantial amount of concrete shielding in the forward direction after the injection septum and the first two bending wagnets of the Booster where most of the electron beam 
losses in the Booster occur. The lead which is placed close to the septum and bending magnet regions absorbs the electromagnetic cascade and the bremsstrahlung produce neutrons in these extra concrete shields. Since these concrete shields extend at least 40 to $50 \mathrm{~cm}$ above the horizontal plane of the beam, they in effect provide the extra neutron shielding necessary for the office area. Radiation montoring of the office area above the Linac-Booster has indicated that operationally over a several month operating pertod the levels produced by machine operation are of the order of 20 to $50 \%$ of the normal back 3 round radiation. Lead and concrete enclosures have been provided for the two beam shutters located in the walls between the Booster and the respective storage rings. In the transfer lines between the booster and the two storage rings, 8" diameter, 12" long lead collars as electron/bremstrahlung shields have been placed around both of the transfer line beam pipes at approximately 2 m spacing along their entire length. Since the expected losses in these transfer lines are less chan $10^{16}$ electron Mev/month the $40 \mathrm{~cm}$ concrete wall around the booster to VUV transfer line where it crosses the VUV experimental floor is sufficient to reduce the yearly doses to less than 1 rem/year which is the DOE design goal for a radiation controlled area.

\subsubsection{Procedure for Securing the Linac Booster Radiation Area.}

There are three primary radiation areas in the NSLS complex, namely the Linac/Booster area, the VUV equipment area inside the VUV storage ring and the $\mathrm{X}$-ray tunnel area. Each of these areas is protected in essentially the same way with regard to radiation produced by the primary electron beam. An electron beam stop (or shutter) with dual electrical interlocks will be inserted in the beam line upstream of any area not secured and interlocked 
in order to prevent passage of the beam beyond that point. In addition appropriate power supplies are interlocked both electrically and mechanically with the safety system in such a way that opening of any entry door will deenergize those supplies and prevent possible acceleration of the electron beam.

A detailed written procedure for entering and securing the Linac/Booster area is given below.

The personnel security system shown schematically in Figure 5 provides the means of assuring that the following steps must be taken before the rf modulators (acceleration of the beam) and Booster magnet and Injection power supplies can be turned on and a vacuum valve/beam stop (immediately beyond the electron gun) may be withdrawn.

1. Before the safety tour is started, a general announcement via the P.A. System requesting all personnel to leave the area is made. Secondly, the emergency exit doorway of the Booster is locked, the Kirk key (A1) is removed and inserted at Station $\$$ 泣 3 on the safety control panel.

2. In order to secure the area two people must be used at all times.

3. The primary operator (Person 1) enters and closes the linac doorway to begin his search as Person 2 remains outside this doorway to prevent access.

4. Person 1 begins the search via a prescribed path (see Fig. 5); depressing stations CS $\# 1$ \& CS \#2 only after it is assured that the area is clear of all personnel. That person then leaves the area via the Linac doorway. The doorway is now locked, the Kirk key (B1) is removed and inserted at station CS $\$ 3$ exterior to the secured area on 


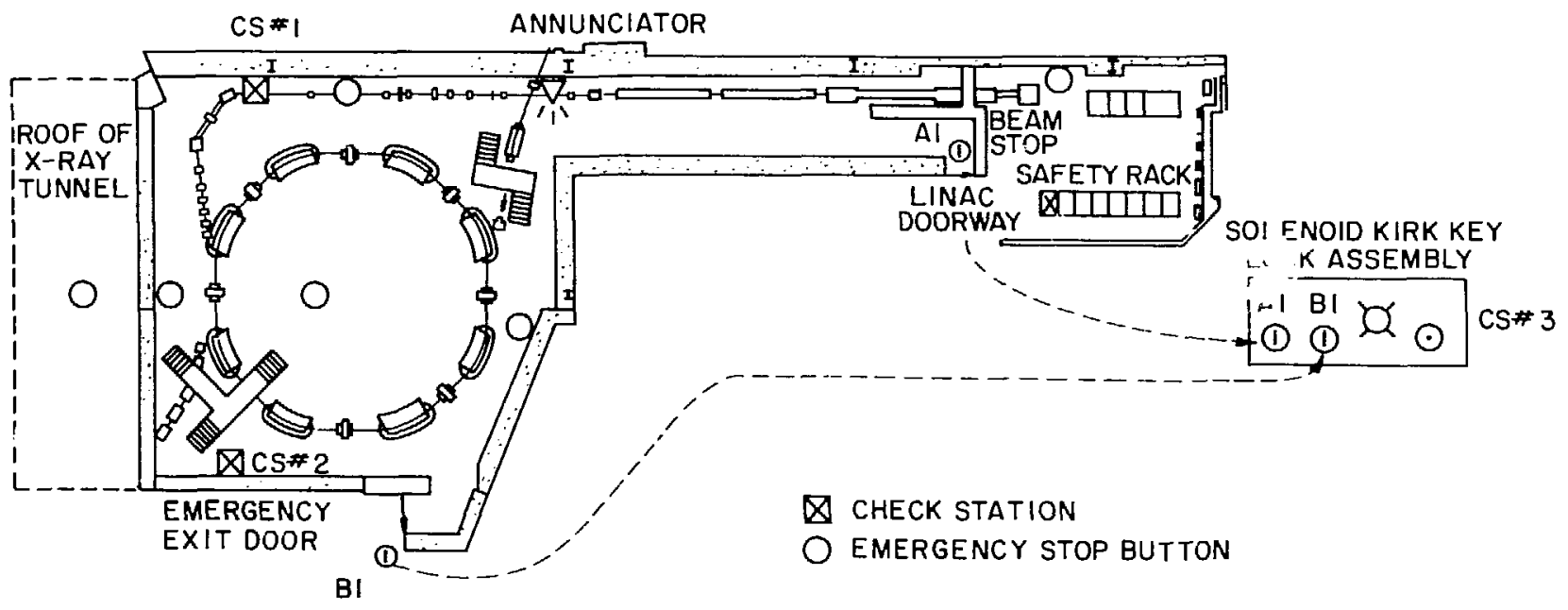

Figure 5. Linac booster floor plan. 
the safety control panel. Insertion and rotation of this kirk key at station CS \#3, only possible if the other key is in place, causes an annunciator to be sounded for a 15 second interval providing that the search was completed within 30 secs. Should anyone for any reason when the Linac Booster is running, feel the need to stop operation; stop buttons are provided both within the Booster Lf nac area as well as exterior to the radiation area protected by this safety system.

5. Both entrances are closed and monitored at all times. Kirk keys interlocked with the $\mathrm{rf}$, magnet and injection power supplies are used to gain entry through the Linac and Emergency doors. Exit from the Linac/Booster area via an emergency breakaway mechanical release system is possible at all times without keys. In addition, should either door be opened dual electrical interlocks initiate an immediate safety response of turning off $r f$ acceleration and all Booster magnet and injection power supplies. The beam stop is also inserted.

6. Both Kirk keys are held captive in the doors when they are open. They are also held captive at station CS $\|^{3} 3$ when the area is secured. 4.3.4 Electrical Safety in the Injection Systems. The electrical power to operate the synchrotron light source is distributed to most of the equipment at 480 volts, 3 phase, with a grounded WYE system. Other power equipment and control equipment is operated from a 115/208 volt system. The installations of this distribution equipment is according to standard industrial practice for equipment of this type and conforms to applicable ANSI National Safety Codes, the National Electric Code. In order to prevent the electrical shock hazard all control and instrumentation systems of the facility are well insulated, have dead front cabinets, and operate at 
voltages less than 30 volts RMS. They are within guidelines set forth in ANSI spec. No. 39.5 (Electrical and Electrical Measuring and Controlling Instrument Safety Requirements) and DOE/EV-0051/1 "Electrical Safety Criteria for Research and Development Activities". Voltages above this 30 volt RMS level for both $A C$ power distribution and $D C$ and $A C$ equipment are under locked or interlocked protection or behind bolted panels and covers according to the service-ability of the equipment.

The cabinets which house high voltage equipment in the Linac/ Booster area are the gun modulator, the klystron modulator and the Booster radiofrequency system power supplies and associated equipment. All entry doors to these cabinets are electrically interlocked so that the high voltage is turned off when the door is openea. In addition, grounding sticks are provided within these high voltage areas. High pulsed voltages are also present in the fast kicker power supply enclosures which provide the power for the injection and extraction septa of the Booster. Removal of the front access panel to this equipment automatically interrupts the high voltage power supply to that unit. All of the high voltage supplies and also the high current supplies for the Booster magnets are dually interlocked with the Linac entry door and the emergency door to the Linac/Booster enclosure so that entry to that area automatically interrupts power to these units.

\subsubsection{Occupational Health Hazards}

4.3.5.1 Non-ionizing Radiation Hazard. The radiof requency

system for the linar accelerator utilizes two high power (20 MW peak) klystrons operating at a frequency of $2856 \mathrm{MHz}$. All of the high power $\mathrm{rf}$ is contained within the vacuum waveguide or accelerator cavity and poses no health hazard. The r idiofrequency system for the Booster synchrotron operates at a frequency of $52.88 \mathrm{MHz}$ and an average power level of $3 \mathrm{~kW}$. 
The radiofrequency power amplifiers were purchased to a specification which required that rf levels from these units shall be below 1 mwatt/sq. cm at 5 cm from the source. Periodic leakage measurements will be made in order to ensure continued conformance to the specification.

Magnetic flelds in the order of 1 KGauss developed by a large permanent magnet are used for focusing the electron beam in the klystrons. Signs warning of this hazard are posted near the magnets. 4.3.6 Accident Assessment for the Injection Systems. Extreme1y high levels of radiation, mainly in the form of bremstrahlung, exist inside the Linac Booster enclosure so the potential for serious radiation accident exists there. In order to prevent such an accident the procedures and protective systems described in the foregoing sections have been implemented so that for an accident to occur the following systems or procedures would have to fail.

1. The dual electrical interlocks on the entry door which automatically inserts the beam stop after the electron gun would have to have failed.

2. The dual interlocks on the entry door which interrupts power to the linac klystrons and the Booster magnet power supply system would have to have failed.

3. The operators who have undergone special training in the safe operation of the facility would have to forget to turn off the power supplies to the linac and booster rf and magnet systems. Alternatively, if someone was locked inside the radiation area when it was secured the following would have to have failed. 
1. The operators must have missed seeing that person during the area search.

2. That person would have to be deaf or unconscious when the warning siren was operated prior to turn on.

In addition to radiation safety, there 1 s : lso the potential for an accident due to electrical shock. Preparation for this eventuality includes regular CPR courses and training in the BNL lockout and tag procedures given in the BNL Safety Manual Section \#1.5.1 for all electronic technicians and others working with high voltage. In addition, the equipment has been designed with appropriate electrical interlocks as detailed in the Sections of this report dealing with electrical hazards.

\section{VUV and X-ray Storage Rings}

5.1 Introduction. The two storage rings are the devices used to store electron beams at an energy of $700 \mathrm{MeV}$. In the $\mathrm{X}$-ray storage ring the beam is also accelerated to a maximum energy of $2.5 \mathrm{GeV}$ after storage at 700 MeV. The electron beams, when bent in the ring's dipole magnets, or special wiggler or undulator magnets, provide the synchrotron radiation for use in the experimental program.

5.2 Storage Ring Operation. Basically the two storage rings operate in the same way, the only fundamental difference being the fact that the fields in the magnetic bending and focusing elements of the X-ray ring are slowly increased in synchronism in order to achieve acceleration. After fast extraction from the Booster synchrotron, a maximum of 5 individual bunches of electrons, spaced at approximately $20 \mathrm{nsec}$ intervals is transported down one or other of the injection transfer lines to their respective storage rings. At the entrance to the storage ring a septum magnet is utilized to 
bend the beam into the storage rings injection orbit and three individual "bump" magnets whose fields collapse in three orbits of the storage ring are used to place the beam in its correct stored orbit. Since the radiofrequency power in the accelerating cavities of the storage ring operate at the same frequency as that of the booster synchrotron, the 5 beam bunches fit precisely into stable "buckets" in the storage rings provided that the correct phase relationship is maintained. Successive accelerating cycles of the booster synchrotron provide further bunches of electrons with the correct phase relationship, though they may arrive at a different time with respect to those electrons already in the storage ring and hence occupy different "buckets". There are 9 available "buckets" in the VUV storage ring and 30 in the $\mathrm{X}$-ray ring so repeated random fillings will eventually fill the rings to a level determined by the quality of the ring vacuum or some instability in the ring system. The injection system is now turned off and the stored beam is allowed to decay naturally in the vUV ring or accelerated to $2.5 \mathrm{GeV}$ and allowed to decay in the $\mathrm{x}$-ray ring. After the decay process has reached the level where a recharge is necessary the remaining stored beam will either be "topped off" by starting up the injection system again or dumped by turning of $f$ the ring radiofrequency power system and then recharging.

\subsection{Hazards and Controls}

\subsubsection{Radiation Hazards from the Storage Rings. The primary} radiation hazard associated with the storage rings is that when the beam electrons strike anything they lose energy by bremsstrahlung and will subsequently not be part of the stored beam. The initial bremsstrahlung radiation which results is primarily localized to a tight forward cone $\theta$ $\left.\mathrm{mc}^{2} / \mathrm{E} \sim 1 / 2 \mathrm{E}(\mathrm{MeV})\right)$ but is so intense that scattering at 1arger angles must 
be considered. The radiation intensity is primarily localized downstream of the places where electrons are lost from the beams, but it is also distributed around the storage rings because of interactions with the residual gas in the beam pipe. Additionally, when the bremstrahlung radiation is absorbed in shield materials, photoneutrons are produced. These photoneutrons result from the giant dipole resonance yielding neutron energies of a few MeV and from the pseudo-deuteron, pseudo-pion, etc., reactions which yield high energy neutrons ( $50 \mathrm{MeV}$ to $E_{\gamma}$ ). The source of the photoneutrons will be localized to where the bremstrahlung is absorbed.

As outlined in section 4.3.1, the electron losses in the linac, linac transfer line, and booster are primarily at $70 \mathrm{MeV}$ or lower energy, are quite intense, and repeat once each repetition cycle of 1 second while the rings are being filled and during tune-up and development times. The electron losses in the storage rings are at higher energies (700 MeV and 2.0 or $2.5 \mathrm{GeV}$ ) and after injection are limited to the number of electrons in a fill and will occur only once per fill. Accident scenarios will not change the energy carried by bremstrahlung radiation but will possibly change how that energy is localized around the ring and thus may affect shield design only somewhat. Accidents may also require an increase in the number of injection cycles required.

\subsubsection{Electron Loss Patterns. Because the pattern of} bremsstrahlung radiation follows the pattern of electron losses around the ring, it is desirable to understand the patterns of electron losses. We assume that an electron is lost from the beam when it strikes the vacuum chamber wall. We expect the beam optics solution and the energy of the electrons to provide a description of the conditions when an electron will hit the wall. 
The magnetic lattices of the storage rings are similar in that they are constructed of several superperiods which are achromatic so that two electrons of slightly different energy entering a superperiod on the same orbit will exit the superperiod on the same orbit again although the orbits are different in the central region of the superperiod. A superperiod contains two bending magnets separated by a short straight section with a quadrupole lens centered between the magneis. In the first bending magnet an electron with lower energy is bent more than one of the standard energy. In the focusing quadrupole the low energy electron is off axis so it is redirected toward the other bending magnet by the lens. It enters the second bending magnet converging toward the primary orbit, is bent more strongly, and emerges on the standard energy orbic. More rigorous descriptions of the optics can be found elsewhere ${ }^{l}$ but the off energy horizontal position function $x\left(p_{1}\right)$ can be related to a standard energy solution $x\left(p_{0}\right)$ by

$$
x\left(p_{1}\right)=x\left(p_{0}\right)+\frac{n \Delta p}{p}
$$

where $\eta$ is known as the dispersion function and is defined by the magnet lattice through the equation

$$
\frac{d^{2} n}{d s^{2}}+\left(K(s)+G^{2}(s)\right) \eta=G(s)
$$

\footnotetext{
${ }^{1}$ S. Krinsky, M. L. Perlman and R. E. Watson, "Characteristics of Synchrotron Radiation and its Sources," to be published in a handbook by NorthHolland. Also BNL 27678.
} 
where $K(s)$ and $G(s)$ repres the strengths of the quadrupole and dipole fields respectively. Figure 6 shows the magnet lattice for one superperiod of the X-ray Ring and the resulting dispersion function. The X-ray ring has elght superperiods. The VUV ring has four superperiods and the lattice is similar to the $X$-ray ring except the quadrupole at the center of the superperiod is split into quadrupoles separated by 1 meter.

When the RF power on a storage ring is turned off the electrons continue to lose energy by synchrotron radiation and strike the inside wall of the vacuum chamber in the regions where the dispersion function is a maximum about 80 us later (for x-ray, $320 \mu s e c$ for VuV ring). Similarly losses due to the Touschek effect (electron-electron collision in the beam) occurs in these regions because the momentum transferred is small.

The loss pattern when an electron collides with a residual gas molecule in the beam line depends on where the collision occurs and the energy of the bremstrahlung photon emitted. At high electron energy the spectrum of bremstrahiung radiation emitted is independent of the target thickness and the material and has the form

$$
n(y) d y d T=\frac{d y}{y}\left(\frac{4}{3}-\frac{4}{3} y+y^{2}\right) d T
$$

where $y=$ photon energy/electron energy and $\mathrm{dT}$ is the target thickness in radiation lengtins. The total bl isstrahlung radiation energy is

$$
E_{b r}=d T \int_{0}^{1} E_{0} y n(y) d y=E_{0} d T
$$

and the remaining electron energy is

$$
E_{e l}=d T E_{0} \int_{0}^{1}(1-y) n(y) d y .
$$

Electrons which emit a low energy photon will be reaccelerated by the $\mathrm{rf}$ system if the energy loss is less than the rf bucket which is $1.5 \%$. 


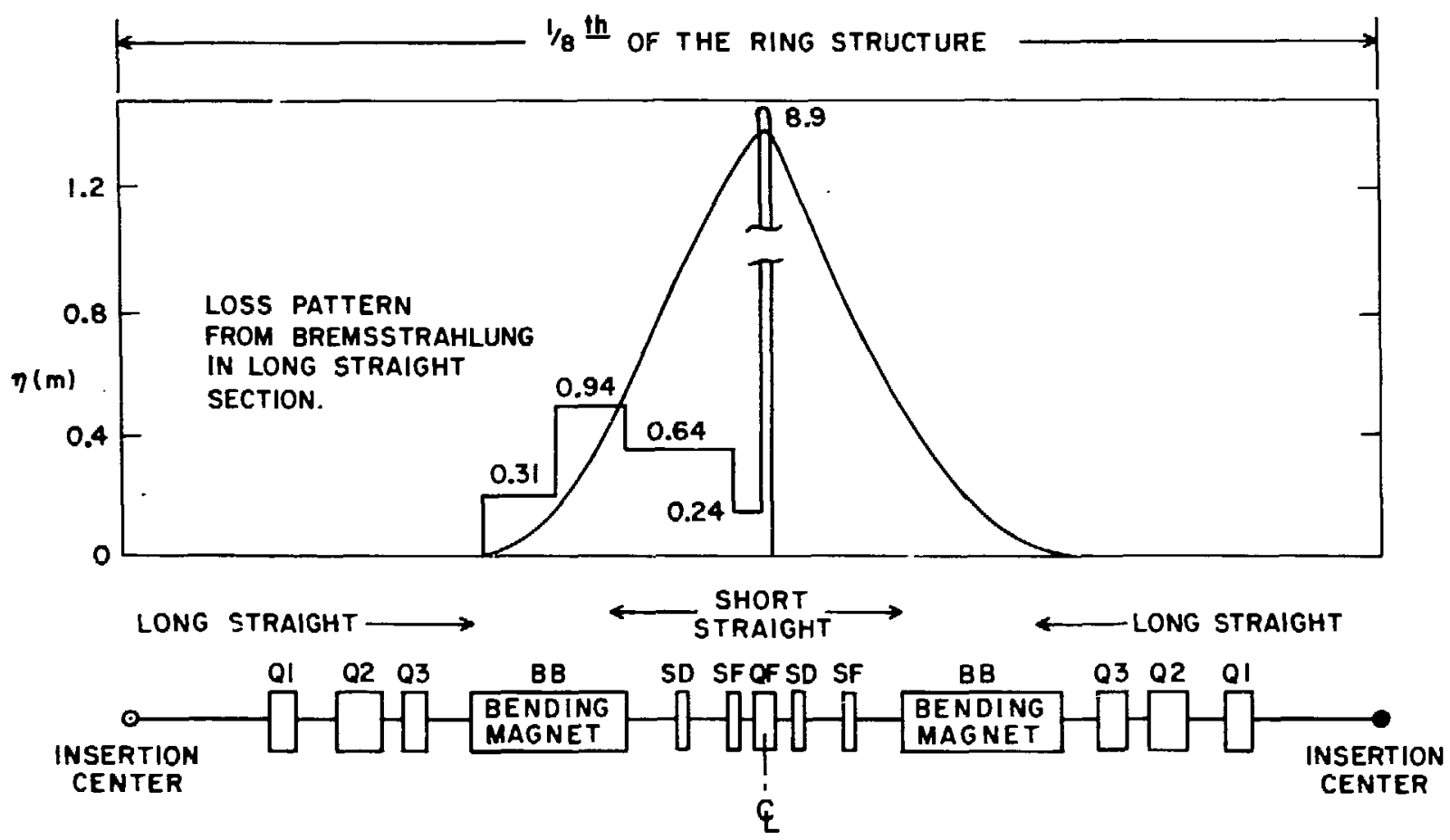

Figure 6. Magnet lattice of $1 / 8$ of the $x$-ray ring. 
Electrons which emit a high energy photon will strike the inside wall of the vacuum chamber at some point. The orbit after a collision at $s_{0}$ given the dispersion function $n(s)$ and its derivative $\eta^{\prime}(s)$ for the lattice is given by

$$
x_{E}(s)=x_{i}(s)-y\left[n(s)-n\left(s_{0}\right)-\eta^{\prime}\left(s_{0}\right)\left(s-s_{0}\right)\right] \cdot
$$

The electron will strike the chamber when $x_{f}(s)=-40 \mathrm{~mm}$. For collisions in the long straight section where the dispersion function and its derivative is zero, the solution is fairly simple and shown on Fig. 6 as electron energy per unit length of chamber wall. Electrons which have enitted photons of energy greater than $\frac{40 \mathrm{~mm}}{\eta_{\max }} E_{0}-0.03 E_{0}$ will be spread over the vacuum chamber wall. Electrons of energy lost between $0.015 E_{0}$ and $0.03 E_{0}$ will deposit at the maximum dispersion points of the ring similar to when the $\mathrm{rf}$ is turned off. Electrons still within the $\mathrm{rf}$ bucket will remain in the beam. Thus the electron energy deposited at the maximum dispersion region is nearly equal to the bremstrahlung energy and about 2.8 times this energy is spread over the beam pipe in the next superperiod. In case of a vacuum accident cited by Blumberg and Perlman, ${ }^{2}$ the fraction of the stored electron energy which can go down that beam line is

$$
\frac{1}{1+1+2.8}=0.21
$$

and depends only on the depth of the rf bucket ( $1.5 \%$ assumed).

The beam loss due to residual gas pressure can easily be calculated. For operation at $10^{-9}$ torr the radiation length $x_{0}$ is $4 \times 10^{14}$ meters. The fraction of energy into bremsstrahlung is

$$
\frac{\Delta E}{E}=d T=\frac{c t}{x_{0}}=\frac{3 \times 10^{8} \mathrm{~m} / \sec 1.3 \times 10^{4} \mathrm{sec}}{4 \times 10^{14} \mathrm{~m}}=10^{-2}
$$

${ }^{2}$ L. Blumberg and M. L. Perlman, "Maximum Credible Radiation Accident," NSLS Memo, May 15, 1980, included as Appendix I of this report. 
The fraction of electrons lost at $10^{-9}$ torr in 4 hours is

$$
\mathrm{dT} \int_{0.015}^{1} \mathrm{n}(\mathrm{y}) \mathrm{dy}=4.8 \mathrm{dT} \text { or } 4.8 \%
$$

If the ring was operating at $10^{-8}$ torr this would be $48 \%$.

This illustrates why the operating pressure in the storage rings must be kept very low.

\subsubsection{Bremsstrahlung Radiation Patterns. The most intense} bremstrahlung radiation field will occur in the thin target of local gas pressure cited by Blumberg and Rerlman. ${ }^{2}$ Approximately one-fifth of the stored energy of the beam will pass in bremsstrahlung through a slice approximately $1 \mathrm{~cm}$ high (at $5 \mathrm{~m}$ in VUV and $15 \mathrm{~m}$ in X-ray ring) and possibly the width of a person's body $(40 \mathrm{~cm})$. The maximum bremstrahlung flux is then $5 \times 10^{9}$, e.q. $/ \mathrm{cm}^{2}$ (equivalent quanta) for the VUV ring and $2 \times 10^{10}$ e.q. $/ \mathrm{cm}^{2}$ for the X-ray ring which corresponds to dose equivalent of 450 and 3800 rem respectively. ${ }^{3}$ These accident doses assume that the source is of optimum dimensions and that no shielding or scatter occurs in experimental apparatus before reaching the individual.

Generally the electrons will be lost by grazing incidence on the alumi num wall of the vacuum chamber allowing for appreciable scatter out of the initial bremstrahlung cone. Dinter and Tesch $^{5}$ have reported the measurements at DESY shown in Fig. 7 of dose rates at large angles from

\footnotetext{
${ }^{3}$ The fluence to dose conversion for bremstrahlung is taken from $\operatorname{Tesch}^{4}$ who calculates these factors for electrons, monoenergetic photons, and bremstrahlung. The values for electrons and monoenergetic photons agree with ICRU 21 .

${ }_{5}^{4} \mathrm{~K}$. Tesch, Nukleonik 8,264 (1966).

${ }^{\mathrm{H}}$. Dinter and K. Tesch, Nuc. Inst. and Meth. 143, 349 (1977).
} 


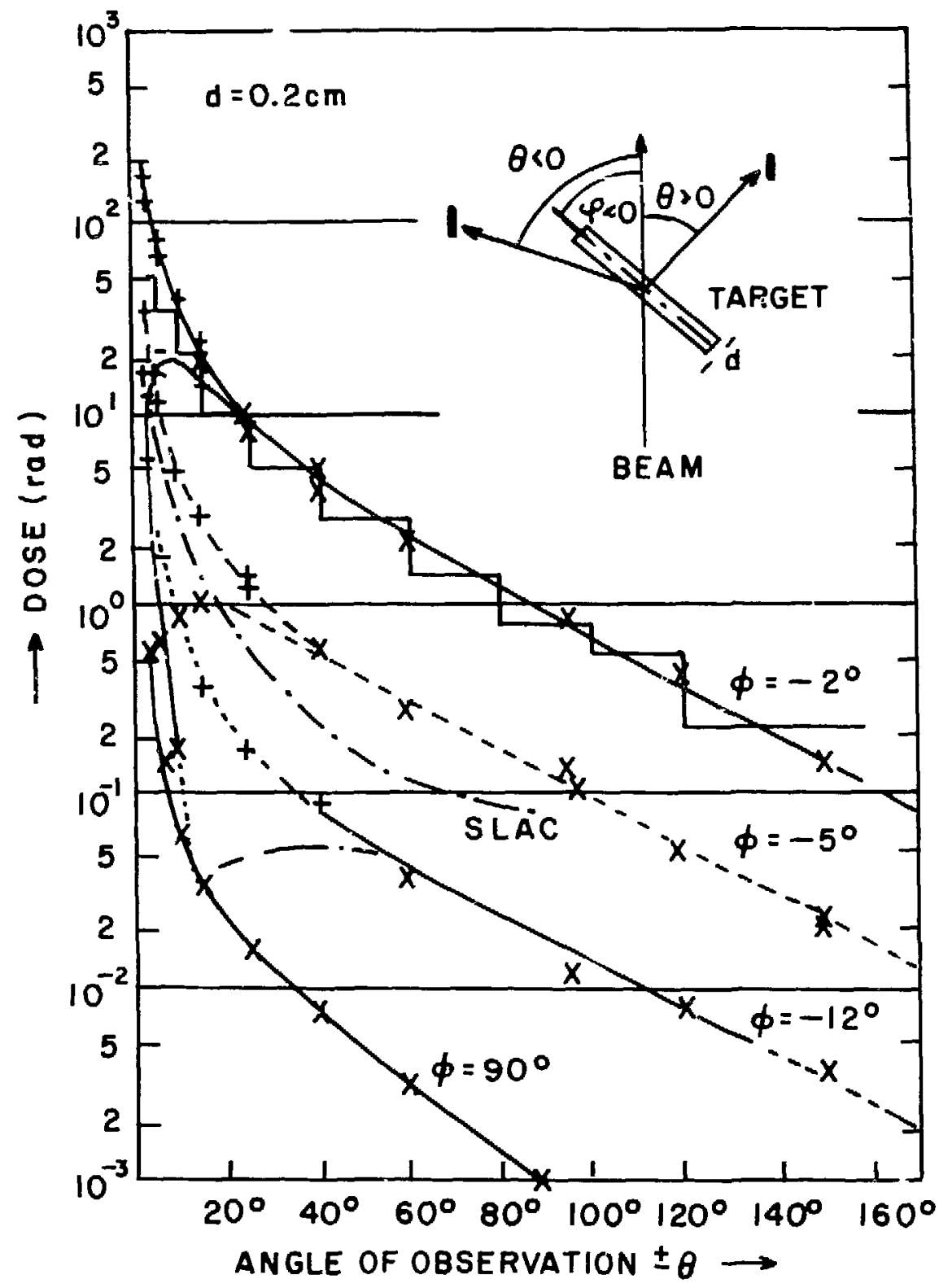

Figure 7. Dose of electron photon stray radiation. 
electron beams passing through thin iron targets. These results can be scaled to the NSLS rings by scaling from the electron energy and target thickness in radiation lengths to give equivalent energy lost in the target. Clearly the most serious problem is at $0^{\circ}$ to the electron motion but the dose at small angles is still appreciable. At larger angles shielding will be necessary only around the electron loss regions. The spectrum of the scattered radiation is softer than the direct bremstrahlung beam. Some shielding is provided by the focusing magnets and the dipoles, and the electron losses will not be uniform around the ring so a case by case consideration will need to be made with respect to shielding thickness and location.

\subsubsection{Shielding}

5.3.2.1 Bremsstrahlung Shielding. The assumptions used in calculating the bremstrahlung shielding on the storage ring at $0^{\circ}$ and on the beam lines are that the design intensity in a ring is dumped 500 times in a year while a particular individual is in the experimental hall. We assume this Individual is standing 1.5 meters from a locallzed sh.eld on a beam line and that $1 / 8$ of the energy stored in the VUV ring (1/16 for $\mathrm{X}-\mathrm{ray}$ ring) strikes the shield at a point. The effective diameter of the shield is taken as $15 \mathrm{~cm}$ and scattered photons are emitted from the surface of the shield. We desire to reduce the annual dose below 500 mrem. Isodose results shown in Fig. 8 reported by b̈athlow et al. 6 from $6 \mathrm{GeV}$ electrons targeted into lead are used to define the length of the shield and the extent that the shield must extend past the shadow of an effective source

${ }^{6}$ G. Bathow, E. Freytag, K. Tesch, R. Kajikawa, and M. Kobberling, Second International Conference on Accelerator Dosimetry and Experience, U.S. Atomic Energy Commission, CONF-691101, p. 222 (1969). 


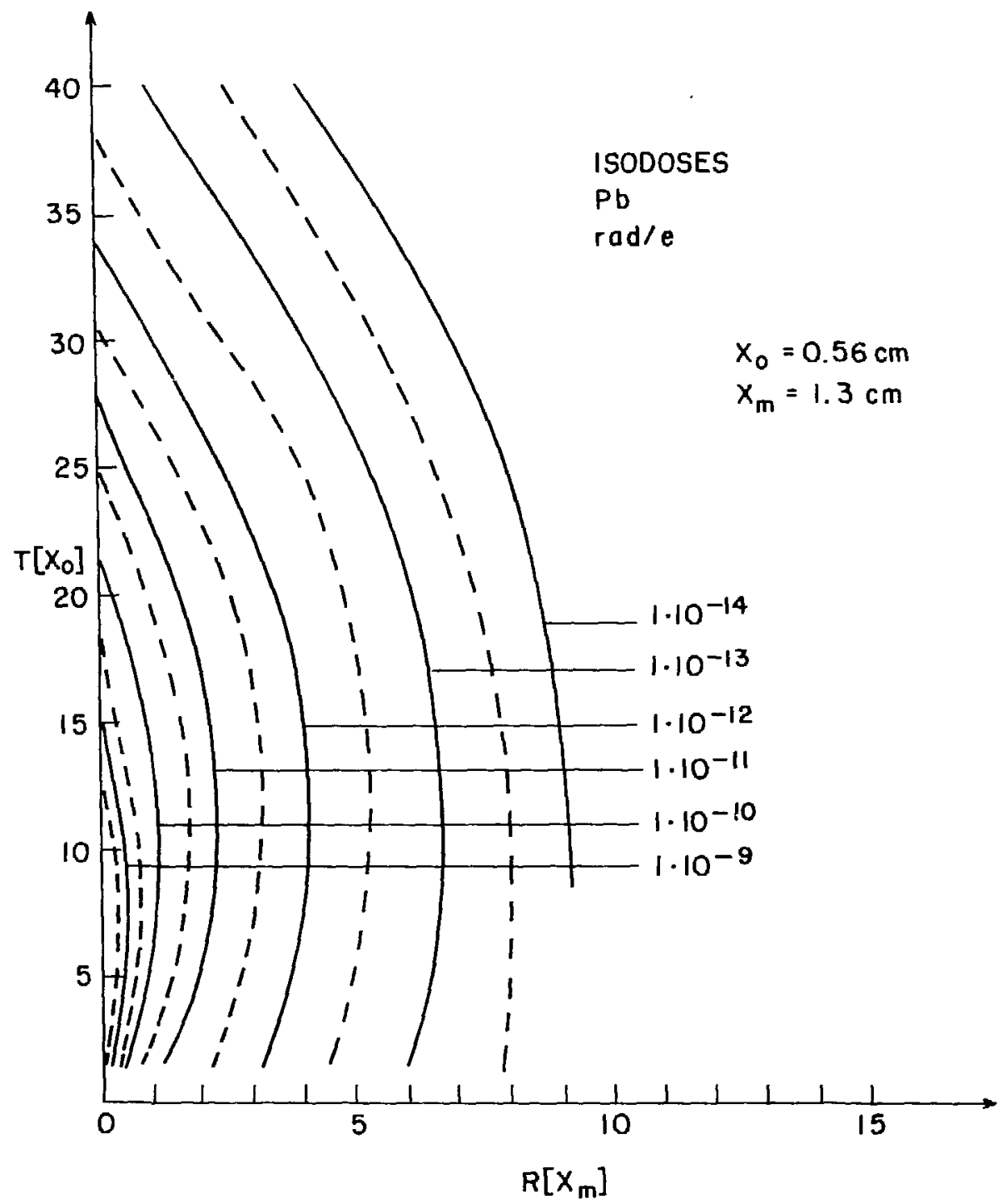

Figure 8. Isadoses for lead. 
and all previous shields. No derating is ipplied for the electron energy difference or for the diffuse shadow and thus larger shield.

The desired isodose curve for the $X-r a y$ ring is:

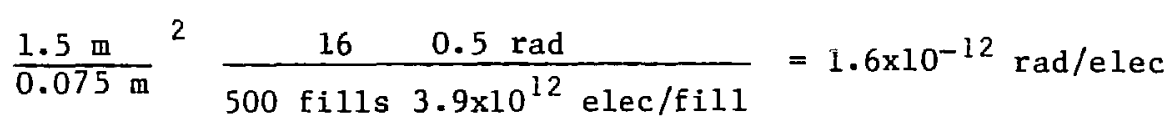

and for the VUV ring is $3.0 \times 10^{-12} \mathrm{rad} / \mathrm{elec}$. The values of the depth intercept in units of the radiation length $X_{0}(0.56 \mathrm{~cm}$ for $\mathrm{Pb})$ and the maximum value of width in units of the Moliere length $x_{m}(1.3 \mathrm{~cm}$ for $\mathrm{Pb})$ define the length of the shield and the extension beyond the irradiated portion of the shield in all directions normal to the beam to the values shown below.

\begin{tabular}{lccc|ccc} 
& \multicolumn{3}{|c|}{ Length } & \multicolumn{3}{|c}{ Extension } \\
& $\mathrm{x}_{0}$ & $\mathrm{~cm}$ & $\mathrm{in}$ & $\mathrm{x}_{\mathrm{m}}$ & $\mathrm{cm}$ & $\mathrm{in}$ \\
\cline { 2 - 6 } $\mathrm{X}-\mathrm{ray}$ & 34 & 19.8 & 7.8 & 4.1 & 5.3 & 2.1 \\
VUV & 31 & 13.0 & 7.1 & 3.4 & 4.4 & 1.7
\end{tabular}

For the $\mathrm{X}$-ray ring the $2.0 \mathrm{GeV}, 1$ amp parameters are used because this is a worst case.

Although these assumptions do not exactly mimic the real situation they are a realistic approximation. There are many more shields which will act as sources but only a few will be close to an occupant and thus contribute to dose. Localizing the energy onto one moderately close shield counterbalances the effect of many shields.

The shield guidelines have been most clearly developed for the shielding on the beam lines where implementation is difficult because the synchrotron radiation and the bremstrahlung radiation occupy the same 
region. These same criteria are applied to the rings themselves in the regions near $0^{\circ}$ to the electron motion. Lead is placed in the outside gaps of the dipoles and around the beam line front ends to intercept rays extending from the electron orbit and inside wall of the vacuum chamber out to about $20^{\circ}$. Most larger angles are also intercepted.

An ongoing effort will be made to evaluate other portions of the rings as to whether or not shielding is necessary in support of an ALARA program using the following considerations. With a realistic source assumption, consider the dose 1.5 meter beyond the restricted area of the shield wall. If the dose is less than 1 mrem per design fill cycle no shielding would be installed. If greater than that the shield would be designed to reduce the dose to less than $1 / 2$ mrem per design fill. Thus shielding the VUV ring long straight section will not be necessary but shielding will be applied in the short straight section at $10^{\circ}-50^{\circ}$ from the first quadrupole.

\subsubsection{Neutron Shielding of Storage Rings and Beam Lines.}

Each of the places where bremstrahlung is absorbed will act as a neutron source from the giant resonance reaction. To reduce the personnel dose due to this process it is critical to absorb as much of the bremsstrahlung radiation as close to the ring (far from personnel) and inside the concrete neutron shield if possible.

As an example, if we assume that near the $X$-ray ring a bremstrahlung shield is stopping $1 / 16$ of the stored energy for $500 \mathrm{fills}$ a year; an individual near the center of the experimental hall and $1-1 / 2 \mathrm{~m}$ from the shield would receive an unacceptable dose of 16 rem. For this 
reason special care has been taken to assure that the high loss region in the short straight sections cannot be seen from any of the beam lines. Alternatively, assume that $98 \%$ of the bremsstrahlung is stopped inside the concrete shield. This component will be about 8 meters from our nominal individual and shielded by $18^{\prime \prime}$ of concrete which will reduce the dose by a factor of 5.5. The total neutron associated dose equivalent is now 424 mrem comprised of 320 mrem $(.02 \times 16)$ from the original source, 100 mrem from the $98 \%$ caught in the tunnel away from the individual, and 4 mrem of high energy neutrons which are barely attenuated by the $27^{\prime \prime}$ of concrete.

These does estimates are for a year at design intensity and serve to emphasize the role of bremstrahlung shield design in an ALARA program. For this reason, modifications to the shielding are being suggested during the beam line design reviews to reduce the size of the oplenings and thus keep the neutron field localized away from the experimenters.

The potential neutron problem at the VUV ring is less severe by a factor of five because the stored energy is smaller, but the gain provided by judicious shielding is reduced due to the smaller area and thinner more transparent shield ( 8 " of concrete which will reduce dose equivalent by a factor of two). Use of depleted uranium for safety shutters and tailpieces will increase the neutron flux by a factor of 1.62 over lead or 1.47 over tungsten.

The dose equivalent on the experimental floors will be reduced by requiring that the safety shutters be closed during injection and when the beams are intentionally dumped by turning off the $r f$ power. 
5.3.2.3 Dose Rate During Injection. The previous sections considered dose rates and shield design based on stored beam operation. When the system is operating beautifully, injection is not a problem because the VUV ring would be filled with 25 pulses and essentially no losses would occur. However, if the system is not functioning correctly the entire dose from a fill can be delivered in only 25 seconds instead of several hours. During injection, all safety shutters will be closed so the bremsstrahlung will not get out onto the experimental floor. This will also confine the neutrons away from the experimenters. Additional shielding has been installed surrounding expected loss regions during injection. If stored beam is not accomplished within a certain limited time (say 2 minutes) it may be necessary to clear the VUV experimental hall until it is accomplis hed.

\subsubsection{Procedures for Securing the Storage Rings}

During the construction and testing phase of the VUV ring, the VUV experimental floor has been kept as an exclusion area and the temporary procedure for securing the VUV area described in Appendix $I$ has been used. When all of the lead and concrete shielding is in place for both the Booster to VUV transfer line and the VUV ring itself, visual inspections and radiation studies will be carried out which will determine whether the shielding is adequate to allow occupancy of the VUV floor at all times including during iniection from the Booster. If the results are favorable the VUV experimental area will remain accessible to persons with film badges at all times. Only the inner section of the ring will then be an exclusion area and the procedure described below will be used to secure this area. 


\subsubsection{1 procedure for Securing the Inner Region of the VUV}

Ring. The safety system requires that the inspecting operators follow a prescribed tour under a fixed time restraint (see Fig. 9). Their function is to clear all personnel from the inner region; they have the final responsibility that a complete search has been made and that no personnel are in the area. The operators will ask any persons in the area to exit with them from the inner ring.

The safety inspection procedure proceeds as follows:

1. An announcement is made over the public address system stating that the inner region of the VUV ring is to be secured in 5 minutes time and that all personnel should leave that area.

2. The tour starts by activation of check station $\|_{1}$ by the stairway over the VUV ring injection straight. SYSTEM RESPONSE

a. The indicator lamp in the check station is turned on. b. A sign mounted near this stairway on the outside of the VUV ring will display a message that the area is not to be entered.

c. The doormat sensors at the top of the stairway are bypassed for 10 seconds to allow the operators to cross over to the inside of the ring. After the 10 seconds the mat sensors are reactivated and anyone passing over them will reset all check stations and the tour would have to be repeated from step 1 .

d. The operators now have 60 seconds to complete the inspection procedures. 
3. Operator $\# 1$ remains just inside the VUV ring at the base of the stairway to check people asserabled there by name. Operator \#2 tours the inner ring area setting check stations 2, 3 and 4 in order and clearing people from the area noting names in the process. SYSTEM RESPONSE

a. The indicator lamp at each check station is turned "on" as each station is activated.

b. For check station \#4 only, activation bypasses the mat switch sensors for 10 seconds to allow the operators to leave the inner ring with any persons found during the tour.Names of individuals are to be checked with operator $\| 1$.

4. Reactivation of check station \#1 at the base of the stairs outside of the ring.

SYSTEM RESPONSE

a. Associated indicator lamp is turned "on".

b. The inner VUV ring area is placed in the "interlock" state.

c. An audible alarm is sounded in the area for 15 seconds.

d. After 15 seconds the shutter in the Booster to VuV transfer line may be opened on command.

At any time the activation of any emergency stop radiation pushpull button will insert the shutter, dump the VUV beam and reset the entire interlock system. These buttons are located on the side walls of the VUV area and one is located in the inner region of the VUV ring. Indicator lamps located in the control room give the status of the shutter and the interlock system. 


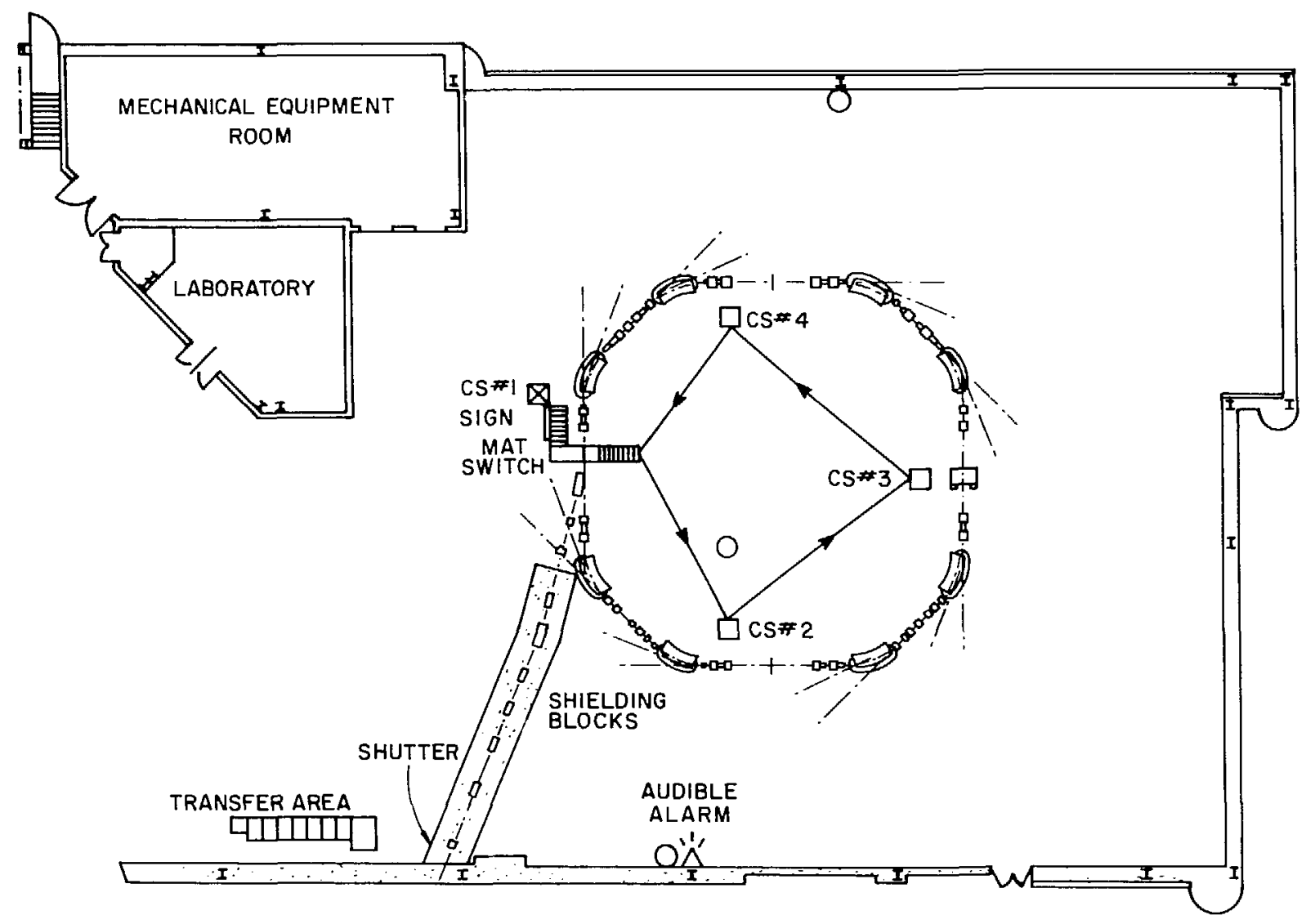

$\triangle$ CHECK STATION

O EMERGENCY STOP BUTTON

Figure 9. VUV safety interlock systems. 


\subsubsection{Procedure for Securing the X-Ray Ring Tunnel Area.}

1. Before the inspection is to be made 2 or 3 public address announcements will be made advising personnel of this fact.

2. The safety inspection will always be conducted by a two person teamof operators. Before entry into the $\mathrm{X}$-ray ring check station $\# 4$ is depressed (Figure 10, X“ray Ring) in so doing the sign at the entrance to the ring will indicate that entry is prohibited by all but the operators. A kirk key is held captive in the station on the entry door. Both operators will enter the X-ray tunnel via the labyrinth entrance, closing the door behind themselves. Once inside the ring check station $\$ 5$ is depressed arming the labyrinth door. Should this door be violated during the inspection tour the entire inspection must be completely repeated. One operator starts the safety inspection tour by walking in a clockwise direction and the other starts the tour in a counter-clockwise direction. It is very important that a careful search be conducted and if personnel are found, their names are to be noted and they are to be advised to assemble inside the ring near the labyrinth entrance way. When the operators reach the 90 and 270 degree points in the tunnel, the associated check stations are to be depressed. The safety check response will be the lighting of the lamp "steady state" in the check station. Both operators will continue the tour to the 180 degree point within the tunnel. This check station is to be depressed. Both operators now continue their tour, still maintaining the clock and counterclockwise walking tours. Should any personnel now be found in the tunnel, the operator must insist they leave with him. The tour includes inspection of all exposed magnet busses for electrical shorts. 


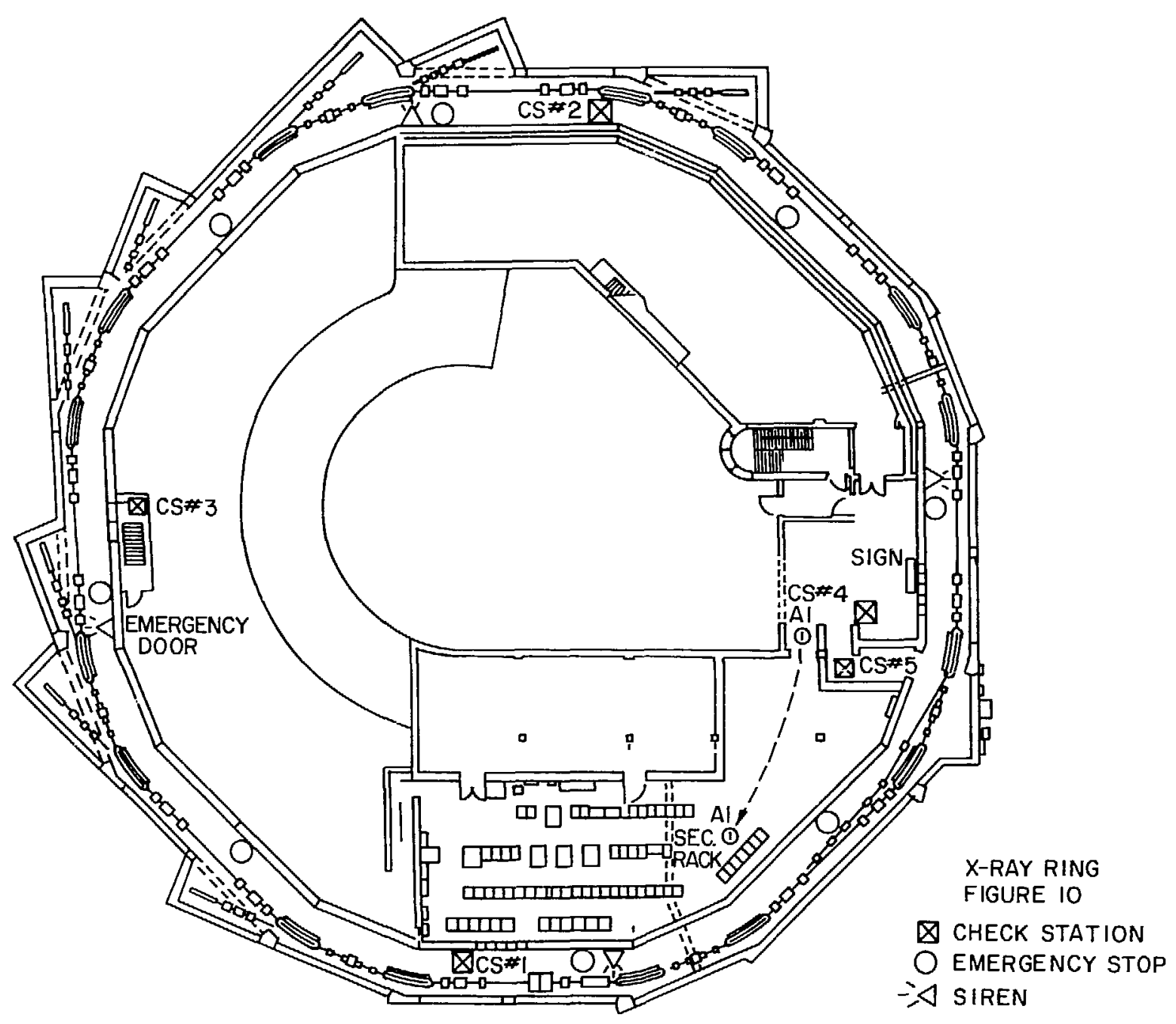

Figure 10. X-ray security system. 
At the labyrinth entrance all personnel assembled must be noted and if names and numbers agree with the operators' findings then and only then will all leave the tunnel. The operators will once again depress check station $\$ 5$ to permit a time period of 10 seconds for tunnel exit. The operators will lock the door behind them, rotate and remove the kirk key and depress the check station outside the entrance way.

The kirk key will now be deposited in its lock assembly located in the X-ray safety rack and rotated. This completes the inspection of the $\mathrm{X}$-ray Ring which is now placed in the "interlock state". This "state" sounds sirens within the tunnel for approximately 15 seconds after which the X-ray's Dipole, Quadrupole, Sextupole, Injection Power Supplies and RF power systems may be turned "on". The safety shutter in the Booster to X-ray ring may now under command be withdrawn.

At any time should any emergency stop button within the ring be depressed or entry into the tunnel be made the safety system will be automatically taken out of "interlock state". This action will shut off the aforementioned power systems and insert the safety shutter between the Booster and X-ray rings.

5.3.4 Electrical Safety in the Storage Rings. The general safety requirements detailed in the first part of Section 4.3 .4 also apply to the two storage rings. Hazards peculiar to the individcal storage rings are discussed herein.

In the VUV ring the magnet power supplies and radiof requency power equipment necessary for machine operation are situated inside the storage ring itself. Wh.en beam is being injected into or is stored in the 
VUV ring, this is an exclusion area which is interlocked as described in Section 5.3.3.1. However, both magnet power supplies and the radiofrequency power equipment may be operated without beam and whilst this inner area is occupied by NSLS personnel. The kicker and fast bump pulsed high voltage supplies are automatically turned of $f$ whenever the inner region of the VUV ring is entered. As in the case of the Injection system hardware, the individual cabinets are all interlocked so that the power is turned of $f$ automatically when the door is opened. In addition, the high current dipole, quadrupole and sextupole magnet bus systems are covered.

The same precautions are taken in the $\mathrm{X}$-ray ring tunnel area except that here the magnet busses are not covered. Instead the magnet and radiofrequency power supplies are dually interlocked with the "Interlocked State" so that they cannot be turned on until the area has been searched and secured.

5.3.5 Accident Assessment for the Storage Rings. The electron beam striking any part of the beam pipe or lead shield in the storage ring can produce very high radiation levels in the form of bremstrahlung. The protection systems described in the foregoing sections are designed to prevent personnel from exposure to these levels. For an accident to occur, the following systems or procedures must fail.

1. The trained operations personnel would have to fail to carry out the prescribed inspection procedures.

2. The interlocks on the entry door which automatically turn of power to the rf and magnet systems must have failed.

3. The interlock with the transfer line shutter which automatically inserts the shutter when the door is opened must have failed. 
4. The interlock which turns off the power to the extraction kickers when the entry door is opened must have failed.

Note that item 2 above is not a requirement for entry to the inner areas of the VuV ring.

All of the above procedures rely upon the operators carrying out an area search and clearing all personnel from an area prior to securing it. The only backup to this is the emergency off buttons which exist in all potential radiation areas and which will inhibit beam operation and revoke the interlock state.

\subsubsection{Occupational Health Hazards}

5.3.6.1 Ozone Production at NSLS. At the PEP facility ${ }^{1}$ ozone production was of some moderate concern but for the PEP ring the critical wavelength is less than $1 / 10$ of the critical wavelength for the NSLS X-ray ring and even smaller for the VuV ring.

Ozone and nitric acid production comes from penetration of the short wavelength part of the synchrotron radiation spectrum. Since our wavelengths are at least 10 times longer, the absorption coefficient of the a].uminum vacuum chamber walls is much greater. At wavelengths of interest (50 and $100 \mathrm{kV}$ ), we have extremely small amounts of radiation in that region. The peak of the PEP ring spectrum is at $40 \mathrm{keV}$ whereas our peak is at $4 \mathrm{keV}$ for the $\mathrm{X}-\mathrm{ray}$ ring. At $4 \mathrm{keV}$ the absorption coefficient of aluminum is 2000 times greater than the coefficient at $40 \mathrm{keV}$. Consequently ozone production is not a problem for the operation of the NSLS storage rings.

${ }^{1}$ The radiation dose to the coll whindings and the production of nitric acid and ozone from PEP synchrotron radiation by $W$. R. Nelson et al., PEP-109. 


\subsubsection{Non-ionizing Radiation Hazards. The radiof requency}

systems for both the VUV and X-ray storage rings operate at a frequency of $52.88 \mathrm{MHz}$ and at maximum average power levels of $25 \mathrm{KW}$ and $500 \mathrm{~kW}$ respectively. The specification for the radiofrequency power amplifier systems required that leakage levels from the cavities associated with this system be below $1 \mathrm{mw} / \mathrm{sq}$. $\mathrm{cm}$ at $5 \mathrm{~cm}$ from the source. Measurements will be made to confirm that these levels are indeed up to specifiction. In the X-ray system power from a driven amplifier operating at an average power level of up to $50 \mathrm{KW}$ is split four ways in a complex power dividing system utilizing standard 1-5/8" E.I.A. transmission line components. The combined power is then fed to the $X$-ray rf cavity which operates in vacuum. Each flange joint in the transmission line system is a potential source for non-ionizing radiation. RF leakage measurements will be made during the commissioning of these systems to determine that the leakage is below $1 \mathrm{mw} / \mathrm{sq}$. cin exterior to the $r f$ cabinet. During operation power levels will be computer moaitored in all stages of the transmission line system on a continuous basis. Periodic radiation loss measurements will be made to ensure system integrity.

Stray magnetic fields from the magnetic components in the storage rings will always be below 20 gauss.

\section{Experimental Areas}

6.1 Introduction. There are 16 beam ports in the VUV and 30 in the $\mathrm{X}$-ray ring and since each port may contain several beam lines, each operated by a separate experimental team, there will be approxinately 100 users operating beam lines at a given time.

Therefore, in order to operate the experimental facilities safely, it is necessary to provide certain administrative controls. Only NSLS 
trained persons will be allowed to operate a beam line. Any intentional violation of the controls will be considered to be very serious and will be dealt with at the Laboratory Director's level. It may lead to a termination of the privilege of using NSLS facilities.

Prior to the final al ocation of beam time on the sSLS facility, every experimental group will be required to submit a description including drawings of their experimental equipment to the Division Safety Committee for review. The exact form of this information and the type of information is given in NSI.S Bulletins 81-19 and 82-7 which are included as Appendices II and III to this report.

\subsection{Experimental Beam Line Operations}

6.2.1 Introduction. Operating beam lines for experiments at the NSLS require connection to a beam port on either the VUV or X-ray storage rings downstream of certain front end components designed, fabricated and installed by NSLS. These "front end components" comprise a photon mask, an ultra high vacuum and fast acting vacuum valve and a safety shutter for both VUV and $X$-ray beam ports. For the $X$-ray ring where all front end components are housed within the $1-1 / 2$ ft thick concrete enclosure beam shutters and beam defining slits may also be utilized.

The water-cooled photon mask is used to protect the ultrahigh vacuum valve from overheating when the valve is closed and therefore is electrically interlocked so that it closes whenever the valve is closed. The safety shutter is provided to stop the bremstrahlung which are produced when electrons strike parts of the storage ring vacuum chamber from reaching the experimental enclosures or "hutches". 
6.2.2 $\mathrm{X}$-ray Beam Lines. In the $\mathrm{X}$-ray experiments the synchrotron radiation after passing through the front end components typically enter a chamber containing a monochromator and/or mirrors to select that part of the spectrum required for experimental usage. The selected radiation then passes through a photon shutter designed to stop the synchrotron radiation while a new rarget is Installed in the experimental chamber or "hutch". In many cases the radiation passes through a Be window just prior to entering the "hutch" and experiments are carried out in a helium atmosphere. The beam line may contain a number of manually or electrically operated vacuum isolation valves and vacuum delay lines.

6.2.3 VUV Beam Lines. For VUV experiments the softer radiation is not able to pass through a thick Be window and the experiments are generally carried out in a vacuum environment. However, for experiments in lithography and for certain biology experiments involving living organisms the beam does pass through a very thin Be window. For vacuum protection several delay lines and a fast valve are provided. Mirror and monochromator chambers are connected immediately downstream of the front end components and typically only monochromatized beams enter the experimental "hutch". The beam from a given beam port may be shared by a number of experimental beam lines each of which will have its own ultra high vacuum valve which in most cases is manually operated.

\subsection{Radiation Hazards in the Experimental Areas}

6.3.1 Introduction. In experimental areas the main hazard is due to electrons at full energy producing bremsitrahlung down the beam pipe (see Section 5.3.2 and Appendix V). The lead and concrete shielding around the 
two storage rings will attenuate radiation levels on the experimental floor to acceptable values. The radiation will come from the slow steady losses of stored beam, from a beam dump and from the rare instance of uncontrolled beam loss in the walls of the orbit vacuum chamber. It is necessary, in addition, to provide protection against the possibility that an experimenter could inadvertently be exposed to hazardous photon beam intensities. Protection against hazards from photon beams must be provided for two wavelength regions, UV and $X$-rays. In the UV range, the danger arises from specular reflections of wavelengths transmissible through the optical windows installed in vacuun chamber walls for such purposes as facilitation of alignment (see Appendix V). An intense reflected beam of this kind can produce eye damage. Hazards from X-ray beams must be treated differently These beams will be usable in the open, exterior to the $\mathrm{X}$-ray opaque beam tubes. Such spaces, in which many of the $\mathrm{X}$-ray experiments are carried out, will be enclosed in "hutches". The metal walls of these "hutches" are opaque to the photons and their openings are interlocked by a keyed system so that they can be accessible only when beam line shutters are clos-d. A detalled description of the Beam Line Safety Control system is given in the user guide which is included as Appendix VI.

6.3.2 Synchrotron Radiation Hazard. This hazard is dominant in the $X$-ray ring where the photons have an assumed average energy of $30 \mathrm{keV}$. Holbourn ${ }^{l}$ has calculated the dose rates and shielding required for the 2 $\mathrm{GeV}, 1 \mathrm{~A}$ daresbury machine and arrives at a dose rate in the beam of $4.2 \times 10^{13}$ $\mathrm{rad} / \mathrm{hr}$ at 1 m from the electron beam. The thickness of steel and lead

\footnotetext{
${ }^{l_{M}}$. Holbourn, Synchrotron Radiation: Dose Rates and Shielding, Science and Engineering Research Council (Daresbury Lab.), Report HP81/141.
} 
required tc stop the full beam at 15 m from the tangent point is calculated to be $1.3 \mathrm{~mm}$ of lead or $14 \mathrm{~mm}$ of iron. The scattered beam which hits the side of the "hutch" is down in intensity by about $10^{5}$ so the side shield which is needed is $0.5 \mathrm{~mm}$ of lead or 4 mm of iron. Since these numbers apply to "white" beams, the NSLS hutches which have been designed with 3.10 mm steel walls all around should be adequate for monochromatic beam. Extra shielding will be added to the walls of the hutches to reduce the radiation levels outside the "hutch" to below 1.0 mRen/Hour.

\subsubsection{Shielding. Returning to the original question as to how to} handle bremsstrahlung down a beam pipe; provision against this hazard includes several elements: Fixed lead shields are installed at the deflection points, external to the tube, to stop any penetrating electrons and absorb bremstrahlung. There will also be safety shutters in the lines close to the emission point to block photons, electrons, and bremsstrahlung whenever downstream safety enclosures are open. In the case of UV beams, deflections at munochromators and mirrors are comparatively large and lead placed at the first point of appreciable deviation from the tangent line will iatercept and absorb bremstrathlung. For the X-ray beans which generally are along lines close to the tangent from the emission point, lead suitably placed at the beam terminus and near monochromators, where the beams are usually displaced by a few centimeters, will absorb any bremstrahlung not intercepted by the external shielding. Quantatative data for this hazard is given in Appendix IV.

\subsection{Beam Line Radiation Hazards Controls}

6.4.1 Introduction. All of the components for beam line safety are designed to be fail safe. Redundant, electrically interlocked, position indicator switches are provided for each safety element. In addition all 
beam lines can be "locked out" of service so that nev: experiments can be safely added while other beam lines are operating. Detailed controls for the beam lines are given in Appendix VI.

6.4.2 Beam Lines Controls. In certain regions of both $X$-ray and VUV beam lines, it is possiole that the bremsstrablung produced by electron losses in the storage ring can emerge from the beam line. Such areas will be protected by a padlocked or kirk key interlocked enclosure to prevent personnel from entering that area. Also certain vacuum valves are in locations which are in direct line of sight to the storage rings and these will be padlocked or kirk key interlocked in the open position so that experimenters may not close them and dismantle the beam line beyond them thus creating a radiation hazard. Removal of such kirk keys will automatically insert the safety shutter for that beam port. Details of the safety requirements for opertion of a beam line at NSLS are given in Appendix IV.

6.5 Fault Analysis of Attempted Entry to an X-Ray Experimental Hutch.

One of the most serious potential radiation hazaard at the NSLS complex is within the $\mathrm{X}$-ray hutch with full $\mathrm{X}$-ray bean present. (White Beam) We therefore analyze the safety provided by the system to be implemented.

A person trying to enter an $X-r a y$ beam line hutch will first require a kirk key which is normally directly interlocked with a photon shutter, or in this case of "white beam" the safety shutter, so that unless the shutter is in place and shielding the hutch from $X$-ray beams the key is 
held captive. Let us suppose that the person desiring entry has acquired another key. (Note that possession of such an illegal key automatically disqualifies that person from all future use of NSLS beams.) In this case the safety shutter will be open as the hutch is entered by means of this second key. However, as soon as the door is opened, hard wired electrical circuits cause several actions to occur.

(a) The safety shutter is closed.

(b) The electron beam in the $\mathrm{X}$-ray ring is dumped.

(c) The unlocked door activates an ionization chamber or area radiation monitor inside the hutch.

(d) An audible and visual alarm operates inside the hutch.

(e) A message is sent to the Control Room Operator indicating that hutch security has been violated.

Since the safety shutter closure operates from a different electrical circuit than the audible alarm, both circuits would have to fail before no indication of a safety hazard is indicated to the person entering the hutch.

It is evident that three separate safety systems would have to fail in order that a person could enter the hutch with $\mathrm{X}$-rays present there and one of these requires possession of an illegal key.

It would be possible for someone to deliberately bypass all the electrical interlocks in order to gain entry and then to acquire the necessary duplicate kirk key to open the door. However, before an experiment is placed on line there will be a check-out procedure which involves inspection and testing of all safety systems so this should uncover any abuses to the system. 


\subsubsection{Occupational Health Hazards}

\subsubsection{Ozone Production in X-ray Experimental Hutches. Cer-}

tain $X$-ray beams may operate in either air or helium atmospheres. Since the photon beam will only pass through a thin beryllium window prior to entering the helium chamber or air in the experimental hutch the absorption of photons due to the aluminum chamber which occurs in the storage ring is nat present here and the ozone production could be several orders of magnitude higher than in the storage ring.

In order to control this potential hazard an exhaust system to the outside atmosphere has been provided for all hutches.

Before an experiment is put on line, ozone levels will be monitored and a time delay for hutch entry established. In experiments where high intensity photon beams are allowed to pass through the atmosphere a calculation of the ozone level will be required for review by the Division Safety Committee. 
APPENDIX I 


\section{PRCCEDURES FOR SECURING THE STORAGE RINGS}

Procedure Eor Securing the VUV Area

\section{(A) INTRODUCTION:}

This procedure will be in effect during the transient time of construction and initial testing of the Booster to VUV transfer line and the VUV Storage ring.

Only after both the transfer and storage ring are operational will this procedure be rudified in the sense that the interior ring of the VuV ring will remain a personnel guarded area and the exterior ring (experimental floor area) will become a controlled access area for staff and visiting scientists. The area will then be considered a low radiation area; therefore all required BNL safety procedures must be followed.

\section{F) GENERAL STATEMENTS:}

This safety system imposes that the inspecting officers follow a prescribed tour under fixed time periods. Their function is to clear all personnel; it remains as with any safety system that the inspectors have the final responsibility that a complete search has been made and that no personnel violate any safety procedure or be left in the area. The inspectors will note names and the number of personnel found during the inspection tour and will instruct them to assemble near the south door.

Before leaving the VUV area the inspectors will count the now assembled group of people found during the inspection tour and only when the count agrees will the inspectors and the assembled group leave the VUV area. (C) SAFETY INSPECTION PROCEDURE: (See Figure 3)

1. Approximately $30,10 \& 5$ minutes before the safety inspection is to be made, public address announcements will be made requesting personnel to leave the area. 
2. Just prior to making the Inspection tour, the gate separating the VUV and $X$-ray area and the air conditioning room's doors are to be closed. The inspecting officers, in doing so, will make a preliminary search and clear personnel.

3. The inspection tour starts by the activation of Check Station \#l located in the hallway by the south door.

SYSTEM RESPONSE

a. The indicator lamp on the check station is turned "on".

b. Two signs, one above the south door and the other on the anchor chain fence located between the VUV and X-ray areas will display a message that the area is not to be entered.

c. The south door sensors are bypassed for a time period of approximately 10 seconds. This time period allows the inspector to enter and close the south doors. After the 10 seconds have elapsed the opening of the door will reset all check stations and the inspection tour would have to be repeated.

d. The inspecstors are now under a time period of 5 minutes to complete the entire inspection procedures.

4. Inspection $\|_{1}$ tours the inner cross sectioned area as per the diagram and inspection $\# 2$ tours the outer area. Activation of Check Station it 2 follows.

SYSTEM RESPONSE

a. The indicator lamp on this check station is turned "on". 
SYSTEM RESPONSE

a. As each station is activated its associated indicator lamp is turned "on".

b. In addition for vucs5 only - activation now bypasses the mat switch sensors on the staircase for a time period of approximately 10 seconds. The time period allows the inspector to leave the inner ring.

6. Activation of Inner Ring Exit Station Check station SYSTEM RESPONSE

a. Associated indicator lamp is turned "on".

b. Up until the tine of the activation of the Exit Station, entry via the south door, anchor fence gate or air conditioning room doors would reset the entire interlock system and the tour would have to be repeated.

After the activation of the Exit Station check station the VUV floor area is divided into two independent sections, one being the inner VUV ring and the other the experimental floor area. Violation of the south door or anchor gate now requires an inspection tour of only those check stations of the exterior ring area of the VuV.

The stairway sensors, if violated, require the entire tour to be repeated starting with check station 1 .

7. Activation of check station 6 (UVCS6).

SYSTEM REPONSE

a. Associated indicator lamp is turned "on". 
b. The south door sensors are bypassed for a time period of approximately 10 seconds. This time period allows all assenbled personnel near the door exit and the inspr.tor to leave via the south door.

8. Activation of Check Station 1 .

SYSTEM RESPONSE

a. The entire VUV area is nlaced $i$ : the "interlock" state.

b. An audible alara is sounded in the VUV area for 15 seconds.

c. After 15 seconds the shutter in the transfer line may be operated via manual control.

The booster is used to charge both the VUV and $\mathrm{X}$-ray storage rings. To assure that the VUV shutter is opened only when a VUV charge is to take place, the extraction magnet power supplies on/off control has been incorporated in the open shutter logic. Without the power supplies being "on" the beam cannot travel to the VUV shutter.

At iny time the activation of the Emergency Stop Radiation Push-Pull buttons will insert the shutter and reset the entire interlock systen. These buttons are located on the side walls of the VUV area and one is Located in the VU''s inner ring.

Indication lamps are provided in the control room to state the position of the shutter and the state of the interlock safety system. 


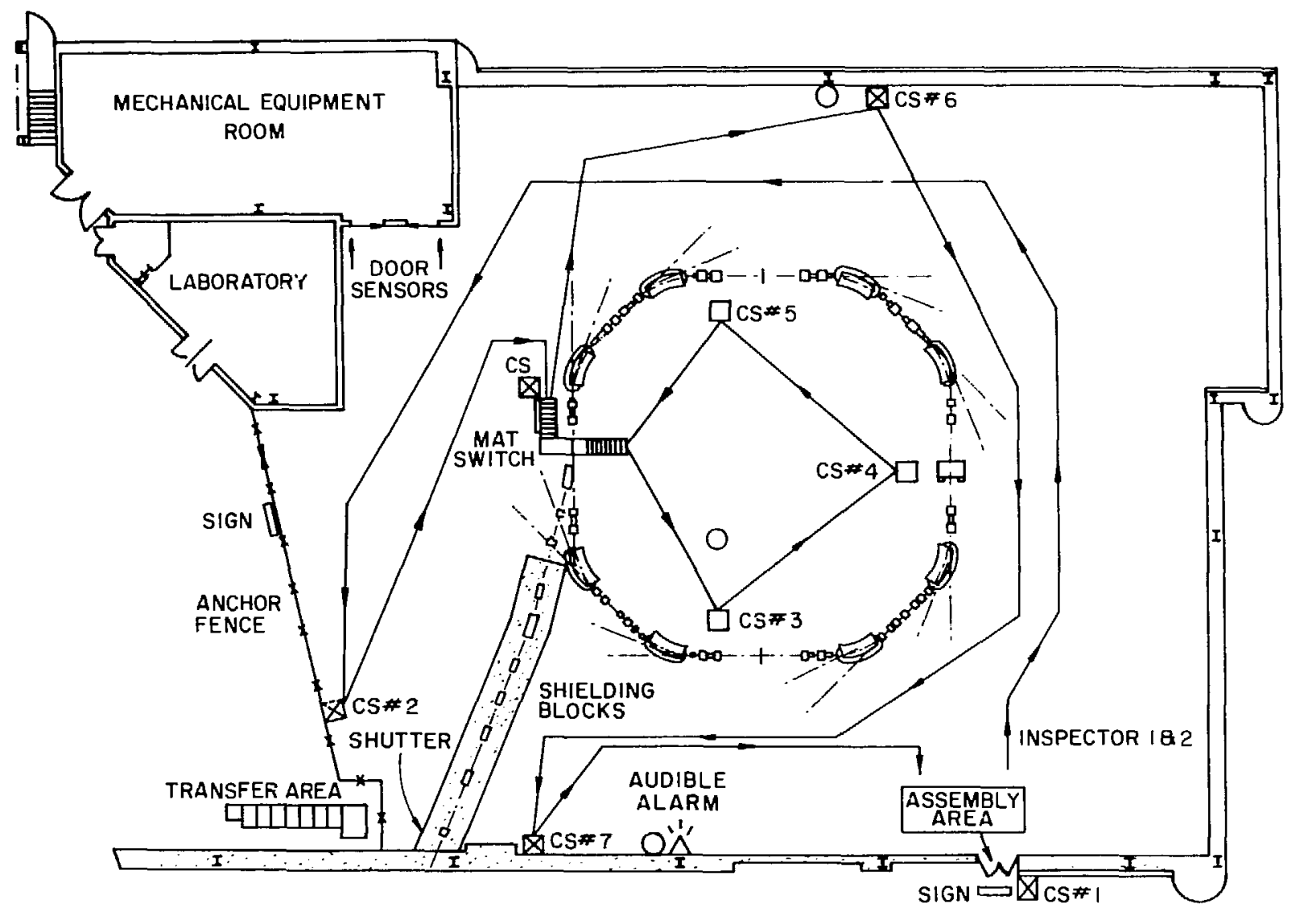

$\triangle$ CHECK STATION

O EMERGENCY STOP BUTTON

Figure A-1. VUV safety interlock system. 
APPENIIX II

NSLS BULLETIN $81-19$ 


\title{
BROOKHAVEN NATIONAL LABORATORY
}

\section{MEMORANDUM}

\author{
DATE: $\quad$ December 10,1981 \\ TO: $\quad$ ALL NSLS PRTS \\ FROM: Jules B. Gode1 \\ SUBJECT: Review of Beam Line Designs
}

We have previously stated that each beam line must undergo a formal review before permission to operate is given. The purpose of the review is threefold to assure that:

the experiment will operate safely with respect to radiation, electrical and fire hazards, and control of toxic materials;

the vacuum integrity of the storage ring and neighboring experiments will not be compromised; and

the space you occupy is within the designated territory and does not otherwise interfere with the functions of the building.

I cannot overstress the importance of adequate preparation for this review. Lack of proper drawings and backup data can result in costly delays. Since it is possible that the review could uncover a problem that will take time to correct, it is prudent to schedule the review 3 to 4 months in advance of expected operation, or sooner, if possible.

We have enclosed guidelines to help you prepare for the review. Your submittal should contain the required drawings, statements and relevant calculations to demonstrate conformance to the standards. The information must be sent to us no less than two weeks in advance of a review meeting to permit the comittee time for study. Four copies of all materials are required. This data will become part of the permanent records of the NSLS and will not be returned to you.

Roger Klaffky will serve as Secretary to the Review Comittee and should be contacted on all scheduling matters. The review meeting should be attended by those in your group who are responsible for design and operation of your experiment. The Review Committee will make its recommendation to the NSLS Division Head who will notify the PRT of his decision to grant permisston to operate.

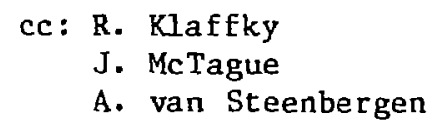

bcc: K. Batchelor

C. Flood

R. Hawrylak

T. Oversluizen

J. Schuchman

J. Sheehan 
NAILONAL SYNCHROIRON LLGHL SOURCE

GUIDELINES FOR BEAM LINE REVIEW

1. Description OF EXPERIMENT

2. DRAWINGS

3. SAFETY

4. VACUUM

5. Space \& Facility Requirements 


\section{DESCRIPTION OF EXPERIMENT}

A brief description of the experiment should include the major pleces of equipment and how they are used. Of importance is such information as the pressures and temperatures at various locations, the duration of a typical experiment, the constituents of the atmosphere in components, target materials, etc.

2. DRAWINGS

a. Overall beam line layout* showing

front end

storage ring and beam line shields

location of support equipment, i.e., racks, tables, computer, etc.

'stay-clear' areas

plan and elevation views

b. Assembly drawings of major components such as monochromators, mirror boxes, experimental chambers, etc. with enough detall to understand their size, general function and materials of construction.

c. Assembly drawings and detail drawings (if required) of any safety-related item such as hutches or photon shutters which are not NSLS designs.

\section{SAFETY}

3.1 Radiation

(Must conform to "GUIDELINES FOR BEAMLINE RADIATION SAFETY", BNL-28384/ NSLS BULI.ETIN 80-4)

a. Radioactive samples or sources: activity, physical state, containment, storage.

b. Passive Shield for line-of-sight radiation

c. Lead Collars

d. Hutch: material and thickness, window, penetration design, door security.

e. Enclosures around Monochromators and Mirror Boxes or alternate method of security to prevent entry into these devices unless safety shutter is closed.

f. specular radiation at VUV ports: Windows, filters.

Note: Interlocks for doors on hutch and enclosure wll be NSLS designs. Alarms and energency beam dump switches wil also be specified by the NSLS.

\subsection{Toxic Materials}

a. Toxic, explosive, flammable samples or materials used in connection with or generated by experiments:

Quentity, physical state, how stored, how contained, how removed, how identified.

\footnotetext{
* We would prefer a scale of 1:50 so that layout can be superimposed on the floor plan of building.
} 


\subsection{Fire}

a. Materials of construction

b. Flammable chemicals and solvents: quantity, storage.

c. Smoke detectors in hutch and other large enclosed spaces.

d. Escape aisles around experiments and ladders for large elevated platforms.

\subsection{Electrical}

Each port will be provided with a $110 / 208 \mathrm{~V} 100 \mathrm{~A}$ panel adjacent to or attached to the shield wall. Experimenters will connect their equipment to the power panel using a cable tray where possible.

Experimental equipment must be designed and installed according to the National Electrical Code and ANSI National Safety Codes. Users are asked to discuss any exceptions to these codes at the safety review.

\subsection{Cryogenic}
a. Types, quantities, and storage of compressed gases.
b. Overpressure protection.
c. Asphyxiation protection in enclosed spaces.

\subsection{Structural}
a. Stability of heavy objects.
b. Platforms and walkways.
c. Pressure vessels.

\section{7 other}

a. Alarms and interlocks for water flow and major water leaks.

b. Protection of electrical equipment from water leaks.

c. Protection of personnel from thermally hot objects.

4. VACUUM

Must conform to "REQUIREMENTS AND GUIDELINES FOR NSLS EXPERIMENTAL BEAMLINE VACUUM SYSTEMS", BNL 28073/NSLS Bulletin 80-2.

Drawings and/or specifications to show:

a. Vacuum components.

b. Materials of construction.

c. Conductance limitations and differential pumping details, conductances, locations, pumping speeds.

d. Gases used in gas phase experiments, gas and flow rate.

e. Window design details, mechanical, thermal, gas permeability.

f. Interlocks, fast valve sensor locations, UHV valve interlocks type and location.

g. If Be window other than standard NSLS design is used, please supply data to show that it will withstand the thermal and mechanical stresses. 


\section{SPACE AND FACILITY REQUIREMENTS}

5.1 Your space requirements on the experimental floor should be covered in the drawing you prepare for Item 2a. Requirements for laboratory, trailer and storage space will be covered elsewhere.

5.2 Utilities: Water: GPM, temperature requirements.

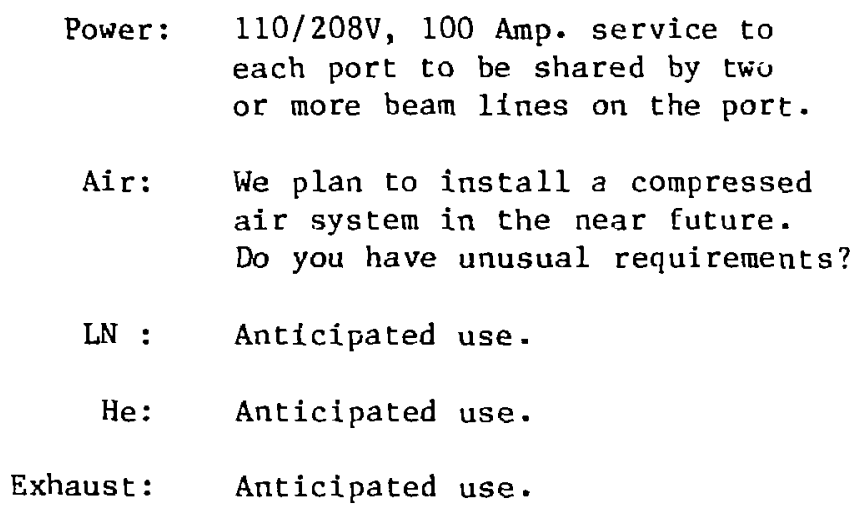

5.3 Will you have vibrating equipment that could affect floor stability? Do you anticipate heavy floor loading that will be shifted frequently? 


\section{BROOKHAVEN NATIONAL LABORATORY}

\section{MEMORANDUM}

DATE: $\quad$ December 7,1981

TO:

FROM : NSLS Personnel van Steenbergen

SUBJECT: Beam Line Review

NSLS Safety Committee Update

In order to accommodate the technical review of beam line design prior to turn on and operation of a particular beam line, I have asked the following personnel to serve on the Beam Line Technical Review Committee: J. Godel, R. Klaffky, J. Hastings, R. Hawrylak, M. Howells, J. Schuchman, W. Thoml inson, G. Williams. Committee.

J. Godel will serve as Chairman and R. Klaffky as Secretary of this

In addition to the technical review, each beam 1 ine design will be subjected to a separate safety review, which will involve a final in situ, safety inspection of the beam Iine prior to turn on. This review will be carried out by the NSLS Safety Committee. The membership of this Committee is in need of an update. Therefore, $\mathrm{I}$ have asked the following personnel to serve (again) as a member of the NSLS Safety Committee: K. Batchelor, T. Oversluizen, G. Schwender, W. Thomlinson, G. Williams, R. Zantopp. As before, as NSLS Safety Coordinator, $K$. Batchelor will serve as Chairman of this Committee. C. Flood* will join this Committee as an ex officio member.

*Safety \& Environmental Division.

AvS/ca 
APPENDIX III

NSLS BULLETIN 82-7

$-77-$ 


\title{
BROOKHAVEN NATIONAL LABORATORY \\ MEMORANDUM
}

\author{
DATE: $\quad$ April 2, 1982 \\ TO: $\quad$ ALL PRTS \\ FROM : $\quad$ K. Batchelor \\ SUBJECT: SAFETY REQUIREMENTS FOR OPERATION OF A BEAM LINE AT THE NSLS
}

\section{Introduction}

In order to operate beam lines in a safe and orderly manner, it is necessary to set clear safety standards and operational procedures for the facility. Guidelines for beam line radiation safety at the NSLS were given in BNL Report \#28384. Among these guidelines was the requirement for a review of the experiment by the NSLS Safety Committee prior to operation. This document is meant to complement BNL Report \#28384 and to aid the user in focussing on some of the specific actions required in order to satisfy the safety requirements.

\section{Shielding Requirements}

\subsection{Bremsstrahlung and Photon Beam Shielding}

2.1.1. The PRT shall provide shielding or an exclusion area for any bremsstrahlung that can be outside the beam pipe or any beam line component downstream from the concrete shield. NSLS will provide shielding within the sawtooth enclosure of the $\mathrm{X}$-ray ring that will assure that no bremsstrahlung will be outside of the tailpiece aperture. Similarly, for the VUV ring, bremsstrahlung shielding will be provided by NSLS up to the exit aperture of the safety shutter. A line of sight diagram must be submitted to NSLS by PRTs showing lead collars, beam stops and exclusion areas. Space is to be provided for possible neutron shielding around the lead. The lead shielding required is detailed in NSLS Bu1letin 82-2. 
2.1.2. Viewports in the vacuum region of all beam lines shall be designed to prevent harmful levels of radiation energing from them. Ports for viewing specular light will normally be covered and the cover shall bear the warning:

\section{"CAUTION - IKTENSE SYNCHROTRON BEAM, DO NOT STARE INTO BRAK".}

2.1 3. Bremsstrahlung shields sheuld be bolted or strapped in place. Any movement of a shield requires approval of an NSLS Safety Officer.

2.1.4. Synchrotron radiation shutters shall be designed so that multiple reflections do not give rise to leakage of radiation beyond the shutter.

\subsection{Manually Operated Sectioning Valve Controls}

2.2.1. The first manually operated beam line vacuum valve shall have a Kirk key operated mechanical interlock which secures it in the open position. All other valves in line ố sight require a similar interlock. NSLS will provide PRTs with designs for systems used on NSLS beam lines.

2.2.2. A Kirk key which is resident in a key exchange base local to the beam line will be held captive under operation of the beam line when the valves are open. If two or more vacuum valves are used in a line of sight beam line a key will be held captive for each valve.

2.2.3. The action of removing a Kirk key from the key exchange base will automatically insert the safety shutter for that beam line. In order to avoid turning off other beam lines connected to the same beam port, a second safety shutter may be used for each line of sight beam 'ine.

2.2.4. The Kirk key may now be inserted in the appropriate vacuum valve where it is held captive and the valves may then be closed.

2.2.5. In order to bring a beam line into operation or return it to operational status, an NSLS Safety Officer must inspect the bean lize to insure that all flanges, shielding, etc., are in place before enabling the interlock system. 
2.2.6. The Safety officer will open the Safety Shuter and may carry out a radiation survey of the beam line before approval for operation is given.

2.2.7 For automatic valves the key exchange base operation w111 automatically close the vacuum valve.

\subsection{Flange Control}

Flanges downstream of a window require a padlock or Kirk key interlock under the control of the Safety officer or, alternatively, a completely enclused exclusion area shall be provided, access to which is by the same kirk key arrangement utilized for the vacuum beam lines.

\subsection{Helium Controls}

Experience with operating beam lines at other laboratories indicates that toxic materials may be produced when the photon beam passes through a beryllium window which is contacting the air. Therefore, all bear lines operating with a helium environment downstream of a Be window sha1l have a helium flow detection system (and alarm) to ensure that no air contacts the window. For a vacuum environment similar controls and monitoring are required.

\subsection{Administrative Requirements}

2.5.1. The PRT shall provide documentation including drawings and circuit diagrams of all PRT designed and installea safety devices and controls.

2.5.2. The following procedures musc be described and filed with NSLS prior to operation of a beam line:

(a) Access to mirrors, monochromator systems, slit systems, beam monitors, etc.

(b) Interlocks and alarms indicating how NSLS operations pezsonnel can respond to an emergency situation. 
APPENDIX IV

NSLS BULLETIN 32-? 


\section{BROOKHAVEN NATIONAL LABORATORY \\ MEMORANDUM}

DATE: $\quad$ April 9, 1982

TO: $\quad$ K. Batchelor, Chairman, NSLS Safety Committee

FROM: W. Thomlinson, R. Watson, L. Blumberg

SUBJECT: Beam Line Bremsstrahlung Shielding at the NSLS

I. INTRODUCTION

The shielding of the NSLS storage rings must be able to deal with maximum credible radiation accidents due to the electron beam being stopped at some spot in a ring and with the maximum credible dosages due to losses during day in, day out operation of the facility. Blumberg and Perlman (BP) considered $^{l}$ a maximum credible accident consisting of a short section of the machine vacuum system, in line of sight of a photon port, brought up to atmospheric pressure and interacting with the electron bean to cause bremsstrahlung. Ryder and Holbourn_subsequently argued ${ }^{L}$ that the radiation hazard from this event was substantially overestimated. We show in this Memo that Blumberg and Perlman's conclusions essentially survive critical reirspection.

Day in, day out losses are important because a ring will be loaded two or three times during a working day with a large part, if not all, of the electrons lost with each loading. This occurs for 250 working days a year for a typical person on the experimental floor. We will consider the radiation due to the interaction of the electron's beam with the residual gas in the machine vacuum of $10^{-y}-10^{-10}$ torr. This is of concern since some of this is in direct view of a photon line. It will be found to be unimportant. Consideration of this is followed by a review of where electron 


\section{INTRODUCTION (Cont'd.)}

losses are expected to occur during normai operation of the ring and this will suggest a maximum credible level of raciation which must be shielded against for such operations. As was the case with the concrete shielding ${ }^{3}$, it is the normal operating losses over a working year rather than an accidental dimp which makes the most severe demands on shielding.

II. Sudden Loss Due to Bringing a Segment of a Ring Up to Air

Consider that a short segment. of the machine vacuum, of $15-20 \mathrm{~cm}$ length, is suddenly brought up to atmospheric pressure. As the electron bunches traverse this region, some of the electrons will interact with the gas and emit bremsstrahlung. The target is thin, of the order of $5 \times 10^{-4}$ radiation lengths, but is traversed many times by any given electron bunch. The frequency of traversal is simply the speed of the electrons divided by the circumference of the ring in question or $-2 \times 10^{6} / \mathrm{sec}$ for the $\mathrm{x}-\mathrm{ray}$ ring and roughly three times this for the UV ring. Given the thickness of the segment, about a millisecond is the time necessary to absorb the electron beam and as this is of the order of the time for valves to close and the ring to turn off, it is very conservative to assume that all the electrons in the ring are involved in bremstrahlung production. Then the total energy in the bremsstrahlung beam is:

$$
E_{Y}=f_{\text {tot }}\langle k\rangle N_{e}
$$

This is BP's $\mathrm{Eq}(9)$ where $\mathrm{N}_{e}$ is the number of electrons stored in the $\mathrm{ring}$ ( $1.06 \times 10^{12}$ for the VUV and $3.9 \times 10^{12}$ for the X-ray at $2 \mathrm{GeV}$ and 0.5 c т.p), $\langle k\rangle$ is the average bremstrahlung energy ( $45 \mathrm{MeV}$ in the VUV and $180 \mathrm{MeV}$ in the $X$-ray) and $f_{\text {tot }}$ is the number of bremsstrahlung associated with any given electron. BP estimated $f_{\text {tot }}$ by asking the probability of any given electron surviving in orbit after one collision in order to be involved in another. From this they obtained:

$$
\mathrm{F}_{\text {tot }}(\mathrm{VUV})=2.94 \text { and } \mathrm{F}_{\operatorname{tot}}(\mathrm{X}-\mathrm{ray})=2.42
$$


II. Sudden Loss Due to Bringing a Segment of a Ring Up to Air (Cont'd.)

and then:

$$
E_{\gamma}(V U V)=22.4 \mathrm{~J}
$$

and :

$$
E_{\gamma}(X-r a y)=272 \mathrm{~J}
$$

Somewhat larger values are obtained if it is assumed that the entre energy of the stored electrons is converted into bremsstrahlung, i.e.:

$$
E_{\gamma}=E \text { (electrons) } N_{e}
$$

or:

$$
E_{\gamma}(V U V)=119 \mathrm{~J}
$$

and :

$$
E_{\gamma}(x-r a y)=1248 \mathrm{~J}
$$

which are the maximum energies possible.

Following BP's method of converting these energies to unshielded absorbed doses one obtains from Eqs(3).

$$
D(\text { VUV })=20,000 \text { Rads at } 5 \mathrm{~m}
$$

and

$$
D(X-r a y)=170,000 \text { Rads at } 10 \mathrm{~m}
$$

where 5 and $10 \mathrm{~m}$ are typical viewing distances along photon beam pipes on the two rings. $R \& H$ use a more conventional technique for converting to dosage which involves dividing the $E_{Y}$ by the electron energies to define equivalent quanta and employing a conversion due to $\mathrm{Tesch}^{4}$ to obtain Rads. This scheme yields values for the doses $D$ which are roughly an order of magnitude smaller than Eqs(4). 


\section{Bremsstrahlung Due to the Residual Gas in Normal Operation}

The same $15-20 \mathrm{~cm}$ of the vacuum chamber considered above can be seen along a photon beam line during normal storage ring operation. The storage ring will operate at a pressure of $10^{-y}-10^{-1 U}$ torr, which is $1.3 \times\left(10^{-1 /}-\right.$ $10^{-13}$ ) of the atmospheric pressure (760 torr) considered for the sudden fallure. Knowing this, it is easy to scale the results of the preceding section. If it takes $100 \mu \mathrm{sec}$ for the majority of electrons in orbit to be lost due to bremsstrahlung production at 1 atmosphere in the $15-20 \mathrm{~cm}$ path, then the time necessary for the equivalent loss at normal machlne vacuum is:

$$
\tau=\frac{100 \times 10^{-b}}{1.3 \times\left(10^{-1<}-10^{-13}\right)} \sim 10^{b} \text { to } 10^{y} \mathrm{sec} \text {. }
$$

A normal work year of 50 forty hour weeks is $7 \times 10^{\circ} \mathrm{sec}$ which is one to two orders of magnitude smaller than $\tau$ implying that the integrated radiation dose seen along a photon beam line over a year is one to two orders of magnitude smaller than the sudden accidental event. Photon beam ports viewing straight sections housing wigglers or undulators will typically see an order of magnitude greater length of machine vacuum and hence will receive a dose which is of the order of, or an order of magnitude smaller than, the accidental dump case.

The rate of loss of electrons due to residual gas bremsitrahlung production can be calculated by noting that for a high energy electron the energy loss in passing through material is

$$
d E=-E_{o} \frac{d s}{x}=\frac{-E_{o} v d t}{x}
$$




\section{Bremsstrahlung Due to the Residual Gas in Normal Operation (Cont'd.)} where $x$ is the radiation length of the material. At a pressure of $10^{-y}$ torr the radiation length for $60 \% \mathrm{H}_{L}, 40 \% \mathrm{CO}$ is $-4 \times 10^{14} \mathrm{~m}$. Thus, for a 4 hour fill time the mean energy lost by an electron is

$$
\frac{\Delta E}{E_{0}}=\frac{c \Delta t}{x}=\frac{3 \times 10^{8} \mathrm{~m} / \mathrm{sec} 4 / 3 \times 10^{4} \mathrm{sec}}{4 \times 10^{14} \mathrm{~m}}=1 \%
$$

Thus, $-1 \%$ of the beam energy at $10^{-y}$ torr will go into bremsstrahlung. This energy will be distributed around the rings in the same manner as is the residual gas.

The fraction of electrons lost due to gas bremsstrahlung interactions can also be estimated by scaling the estimates made earlier. First, $\tau$ must be reduced by the ratio of the ring circumference to the $20 \mathrm{~cm}$ path 1 ength since electron losses occur uniformly around the ring. The result is the time required to lose the full beam in the full ring. The fraction lost during a sintie 4 hour fill is then found to be of the order of $4.8 \%$.

\section{Location of Electron Losses During Normal Operations}

Neglecting injection and the effects of inserting devices which act as scrapers, the normal processes by which electrons will be lost involve electron-electron, bunch-bunch, and to a lesser extent, electron-residual gas scattering which leave electrons in orbits and at energies outside the phase space region in which they can be matntained in energy by the RF system (see, for example, Krinsky, et $a l^{b}$ ). Whether initially at too high or too low an energy to be in the RF bucket, the electron will lose energy and spiral inwards in orbit until it collides with the inner vacuum chamber wall. For a vacuum chamber of unfform cross-seztion, this will most 
IV. Location of Electron Losses During Normal Operations (Cont'd.)

probably occur where the dispersion function, $n$, is a maximum. This quantity relates the horizontal error in orbit positions, $\Delta x$, to the error in electron momentum, $\Delta p$, namely:

$$
\Delta \mathrm{x}=\frac{\mathrm{n} \Delta \mathrm{p}}{\mathrm{p}}
$$

(see Eq. 73 in ref. 6 and the associated discussion). This is plotted for the NSLS $X$-ray ring in Fig. 1 and similar behavior occurs in the VUV ring. The electron optics of the NSLS rings were designed so that $n$ is zero in the long straight sections, housing wigglers and undulators, is near zero in the bending magnets and peaks in the middle of the short straight sections between pairs of bending magnets. The initial collision of an electron with the vacuum chamber is expected to occur on the Inside wall of these short straight sections with a $95 \%$ probability. Therefore, there must be a concentration of shielding lead alongside and downstream of these short straights.

It is seen from Fig. 1 that the maximum $n$ for the $X$-ray $r i n g$ is $1.4 \mathrm{~m}$ ( $1.5 \mathrm{~m}$ for the VUV). Since the distance between the center of the vacuum chamber and inner wall is $0.04 \mathrm{~m}$, the momentum deviations at which electrons hit the waII is $\frac{\Delta p}{p}=\frac{0.04}{1.4}$ or roughly $3 \%$. Now, it was noted in section III that roughly five percent of the electrons will be lost due to residual gas bremsstrahlung production during a four-hour sinift. The typical energy or momentum loss in such an event (see Section III) is $6 \%$ in the VUV and $9 \%$ in the $x$-ray ring. These electrons can be expected to hit the vacuum wall in or just upstream of the first short straight section encountered after the event. This has two implications: first, electrons will not survive to be 


\section{Location of Electron Losses During Normal Operations (Cont'd.)}

involved in a second event of this nature and hence the estimates of

Sections II and III are over estimates, and second, if the electrons make it to the next short straight, they are expected to hit the wall when $0.04 / \mathrm{n}$ equals 0.06 in the VUV and 0.09 in the X-ray rings, $1 . e .$, when $\eta$ equals a half and one-third its maximum values respectively. This implies that, while most electrons are lost by gradual processes and first hit the wall at the center of the short straights where $\pi$ is a maximum, some one-percent of the electrons will tend to hit the wall upstream of the center. The above observations do not apply to electrons involved in substantial bremsstrahlung energy losses in regions where $n$ is large. The distribution of where these electrons will hit the wall is, as of this writing, unknown. Orbit calculations are being done to help answer the question. This discussion implies that shielding must be considered along the short straight sections and extending back into the dipole magnet.

\section{The Maximum Credible Steady State Dosage}

Granted that there are eight short straight sections in the $\mathrm{X}$-ray ring (and four in the VUV), a maximum credible estimate of the dosage occurring and hence the shielding needed along a photon beam line can be made by assuning that one-eighth (one-fourth) of the electrons are stopped in one short straight section, that their energy is converted to bremsstrahlung, and that this imoinges on a single photon port. If no bremsstrahlung attenuation is credited to the aluminium, steel and lead along the straight section and, if all the electrons in a loading are lost, then from Eqs. 4 we have unshielded dosages of:

$$
D(V U V)=\frac{20,000}{4}=5,000 \operatorname{Rads} / \text { Load at } 5 \mathrm{~m}
$$


and :

$$
D(X-\text { Ray })=\frac{170,000}{8}=20,000 \operatorname{Rads} / \text { Load at } 10 \mathrm{~m}
$$

for one cycle of machine operation. The numbers are an order of magnitude less if one prefers the equivalent quantum method of estimating dosage.

It is expected that an electron beam will have a half $11 \mathrm{fe}$ of -4 hours. After four hours the beam will be dumped and a new beam injected, though it may prove possible to replenish the electrons in the existing beam without dumping it. In any case, it appears reasonable to assume two complete loadings per working day. Granted 250 working days a year, the allowable dosage per loading must be $1 / 500$ of the allowable annual dosage. Let us take this to mean that Eqs (7) must be reduced by shielding to less than $1 \mathrm{mRad} /$ Load (i.e., $0.5 \mathrm{rad} /$ year for the maximum allowable radiation leve1), a factor of $5 \times 10^{-b}$ for the $\times$-ray ring and $2 \times 10^{-1}$ for the UV ring. The necessary lead shielding can be estimated in three ways:

1) Dinter and $\mathrm{Tesch}^{\text {b }}$ report a measured effective linear absorption coefficient of $0.47 \mathrm{~cm}^{-1}$ for bremsstrahlung in lead. This implies that $-14^{\prime \prime}$ of lead is needed on the $\mathrm{X}$-ray ring along the direction of the beam, and $13^{\prime \prime}$ for the UV ring.

2) One can take the estimate of attenuation following Rossio which accounts for the electromagnetic cascade. This is summarized in Fig. 2 for a $2.5 \mathrm{GeV}$ electron beam. One obtains a required thickness of lead of 55 radiation lengths or about 12 " for the $\mathrm{x}$-ray ring. 


\section{The Maximum Creaible Steady State Dosage (Cont'd.)}

Dinter and Tesch made measurements ${ }^{b}$ of the dose and shielding parameters of electron bremsstrahlung radiation produced by a high energy electron beam impinging on iron targets of varying thickness. The bremsstrahlung production is concentrated in the forward director in a cone whose opening angle is a fraction of a milliradian and, unfortunately, the smallest angle of observation was necessarily much larger than this. Their measured dosages are thus much smaller than the numbers above. Dinter and Tesch's results do suggest that radiation generated at right angles to the forward direction is only four or five orders down in magnitude. This is still too large to be ignored in shielding considerations.

The results of Monte Carlo calculations (Fig. 6 and 7 of Ref. 5), indicate that the bremsstrahlung produced at angles of $30^{\circ}$ and $90^{\circ}$ is 2 or more orders of magnitude lower in energy than in the forward direction. The energies are also below the energy necessary for resonant neutron production. Referril.g to their Figure 5, it is clear that the concrete shielding provided by the $\mathrm{X}$-ray tunnel should provide adequate shielding.

3) The most straightforward estimates for the lead shielding along a beam line are probably those obtained using the data of Ref. 9, G. Bathow, et al, for the isodoses in lead for both longitudinal and radial directions. These estimates are not greatly different than those above, and will be used to make recommendations for beam line lead bremstrahlung shielding. However, these estimates have calculated doses at the edge of a shield. We will choose to assume that a worker's annual occupancy of the experimental floor is approximated by 
V. The Maximum Credible Steady State Dosage (Cont'd.)

standing $-1.5 \mathrm{~m}$ from a shield during 500 fills of the ring. In actuality, there will be many shields, the dose from each one will be smaller than this. Efforts will be made to keep the shielding as close to the ring as possible.

We would like to make the dose less than $0.5 \mathrm{rad} / \mathrm{yr}$. at a distance of 1.5 meters from the lead shielding. The effcctive source of radiation will be a volume in the lead with a typical dimension $\mathrm{r}$ the order of $15 \mathrm{~cm}$ diameter. The $\mathrm{R}^{-2}$ factor will then be $2.5 \times 10^{-3}$. Thus, the yearly dose at the surface of the lead can be $D=200 \mathrm{rad} / \mathrm{yr}$.

Assume $1 / 8$ of the electrons in the VUV ring and $1 / 16$ of the electrons in the $X$-ray ring lose their energy down a beam line each fill. For 500 fills/year that means a beam line will see $N$ electrons where $N=500 \times 1 / 8 \times$ $N_{e}$ for the UV and $N=500 \times 1 / 16 \times N_{e}$ for the $X$-ray ring. $N_{e}$ is 1.06 $\times 10^{12}$ for the VUV and $3.9 \times 10^{12}$ for the $X$-ray ring. Thus, for the UV ring, $N=6.63 \times 10^{13} \frac{\mathrm{e}}{\mathrm{yr}}$ and for the $\mathrm{X}$-ray ring $\mathrm{N}=1.22 \times 10^{14} \mathrm{e} / \mathrm{yr}$.

The proper isodose curve on Fig. 3 is then found by:

$$
\text { ISODOSE }=\mathrm{D} / \mathrm{N} \quad \frac{\mathrm{rad}}{\mathrm{e}}
$$

The values of the depth intercept in units of the radiation length $x_{0}$ and the maximum value of width in units of the Moliére length $x_{m}$ then define the length of the lead and the thickness required in all directions normal to the beam, respectiveiy.

$$
\begin{aligned}
\text { X-Ray: ISODOSE } & =1.6 \times 10^{-1} \mathrm{rad} / \mathrm{e} \\
\text { Length } & =34 \mathrm{X}_{\mathrm{o}}=19.8 \mathrm{~cm}:=7.8 " \\
\text { Thickness } & =4.1 \mathrm{X}_{\mathrm{m}}=5.3 \mathrm{~cm}=2.1 "
\end{aligned}
$$

VUV: ISODOSE $=3 \times 10^{-12}$

$$
\begin{aligned}
& \text { Length }=31 \mathrm{x}_{\mathrm{O}}=18.0 \mathrm{~cm}=7.1^{\prime \prime} \\
& \text { Thickness }=3.4 \mathrm{X}_{\mathrm{m}}=4.4 \mathrm{~cm}=1.7^{\prime \prime}
\end{aligned}
$$




\section{v. The Maximum Credible Steady State Dosage (Cont'd.)}

In order to determine the placement of lead shielding along a beam line to obtain line-of-sight shielding, the proper aperture for the bremsstrahlung radiation is the lead collimation. The collimation is provided by the tailpieces, the ring belt and the lead to the inside of the ring. Since the electrons strike the inner wall, the lead on the inside of the ring prevents line of slght to the inside walls of the straight sections, The effective source for the brensstrahlung is not a simple point source at the nominal tangent to the beam. In the shielding considerations, the source must be zaken as a rectangle at the tangent with a vertical extent $\pm 10 \mathrm{~mm}$ from the median plane, extending horizontally $30 \mathrm{~mm}$ towards the outside of the orbit and $100 \mathrm{~mm}$ towards the inside of the orbit. All lines of sight through the lead collimators back to this extended source must be blocked by the above mandatory lead shield thicknesses. Any place along a beam line where the direct bremsstrahlung radiation is outside the beam pipe will be an exclusion area for personnel. VI. Neutron Shielding

When the lead stops the high energy radiation some conversion of personnel photon dose to neutron dose occurs $\left(-10^{-4}\right)$. The concrete walls around the X-ray ring, and those along the VUV ring wf.11 suffice to attenuate the neutrons from the internal shielding. However, the actual bremstrahlung dose to any particular lead shield, and thus the subsequent conversion to neutrons, is so uncertain that we feel it is unnecessary to initially install neutron shielding around each beam line shield. Once operation begins, neutron dose levels must be monitored, and neutron shielding installed wherever necessary. Thicknesses of neutron shielding tend to be large so the most effective reduction of neutron dose may come from making apertures in the lead shields smaller, thus moving the source away from the experimenters. Ideally, the lead shielding would be inside the concrete shield wall. 


\section{Conclusions:}

The calculations and recommendations presented in this Memo have been based on extreme worst case assumptions for the normal beam losses. No attempt has been made to estimate an occupancy factor for any individual. We feel that the radiation levels have, there Jre, probably been overestimated by two or three orders of magnitude.

Based on the calculations in this Memo, the following conclusions are then reached:

1. The residual gas bremsstrahlung dose for one year of operation is expected to be roughly equivalent to a single sudden event. for straight sections, and less on a bending magnet port which does not see a straight.

2. The maximum credible steady state dosage due to electrons hitting the inner wall of short stralght sections is higher than the extreme gas hremsstrahlung accident.

3. The recommended mintmum dimensions of lead which must be used to provide line-of-sight beam line bremsstrahlung shielding are tabulated below:

\begin{tabular}{|l|c|c|}
\hline \multicolumn{2}{|c|}{ Paralle1 to Beam } & Normal to Beam \\
\hline X-kay & $8^{\prime \prime}$ & $2^{\prime \prime}$ \\
\hline VUV & $7^{\prime \prime}$ & $1.7^{\prime \prime}$ \\
\hline
\end{tabular}


VII. Conclusions: (Cont'd.)

4. The bean line shielding installed must be monitored and radiation levels measured during operation. The position and thickness of the shielding must then be adjusted to satisfy the allowed dose conditions.

5. The need for neutron shielding around the lead bremsstrahlung shields will be evaluated as necessary when operations begin. 


\section{REFERENCES}

1) L. Blumberg and M. L. Perlman "Maximum Credible Radiation Accident", NSLS Memo, May 15, 1980.

2) R. Ryder and M. P. Holbourn, "Addendum to HP81/139, Daresbury, November, 1981 .

3) National Synchrotron Light Source Design Handbook, Sect. 29.

4) K. Tesch, Nubleonik, 8264 (1966).

5) H. Dinter and K. Tesch, Nuc. Inst. and Meth., 143, 349 (1977).

6) S. Krinsky, M. L. Perlman and R. E. Watson, "Characteristics of Synchrotron Radiation and It's Sources", to be published in a handbook by North-Holland.

7) National Synchrotron Light Source Design Haadbook, Sect. 3.2.

8) Rossi, High Energy Particles, p. 251 (:961).

9) G. Bathow, E. Freytag, K. Tesch, R. Kajikawa, and M. Köbberling, Second International Conference on Accelerator Dosimetry and Experience, U.S. Atomic Energy Commission, CONF-691101, p. 222 (1969). 


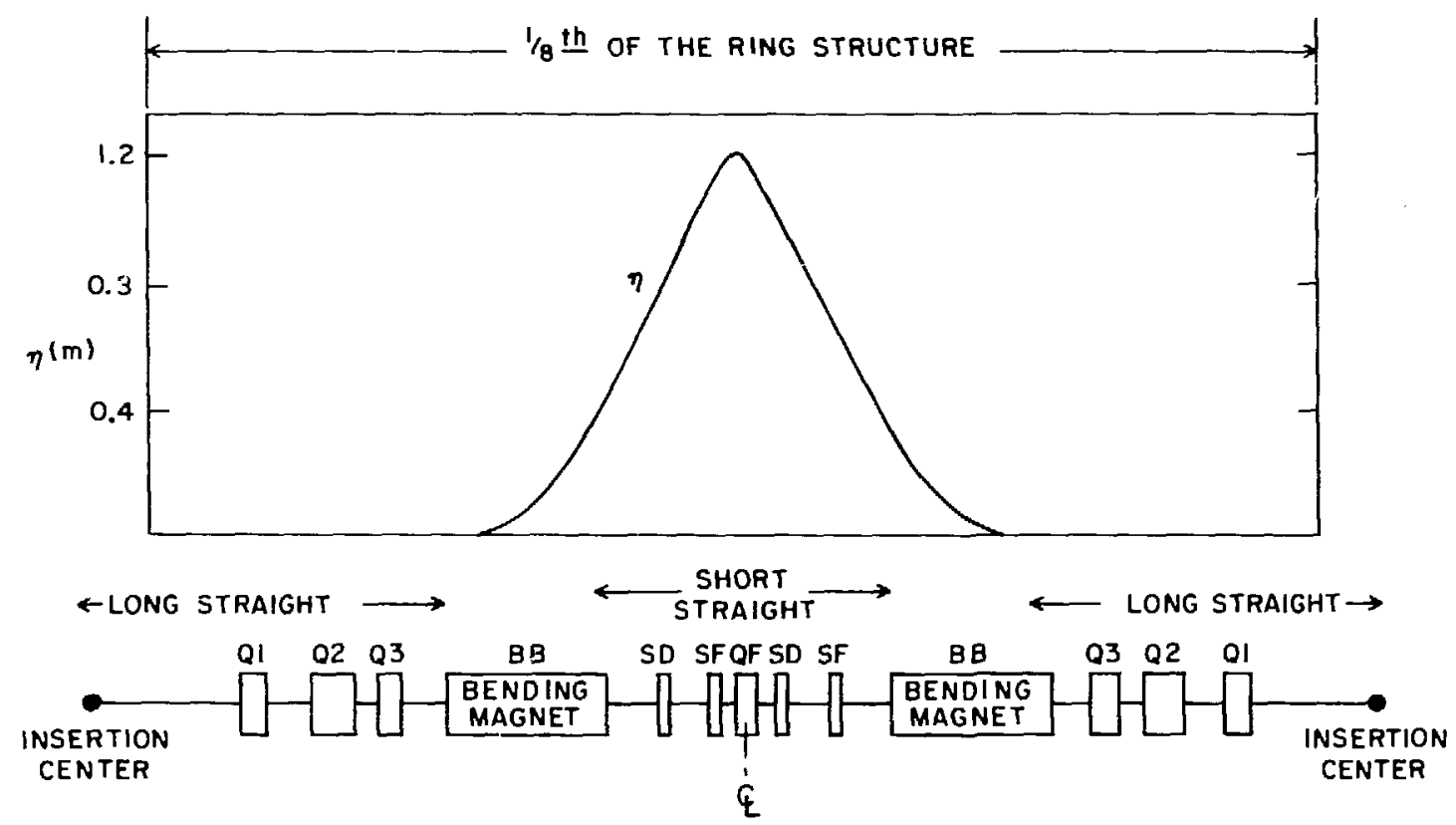

Figure D-1. The momentum dispersion function for the NSLS $x$-ray ring. 


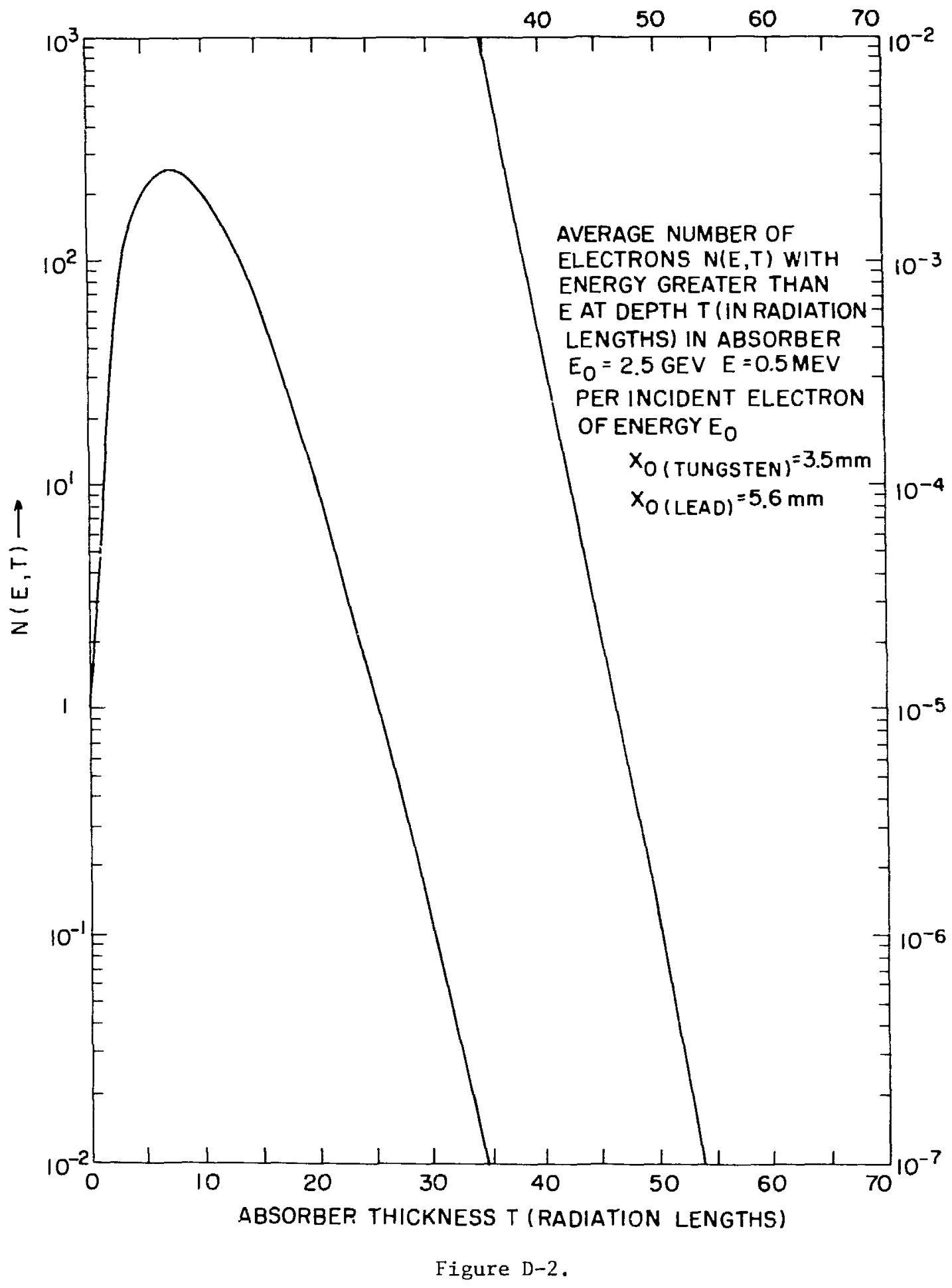




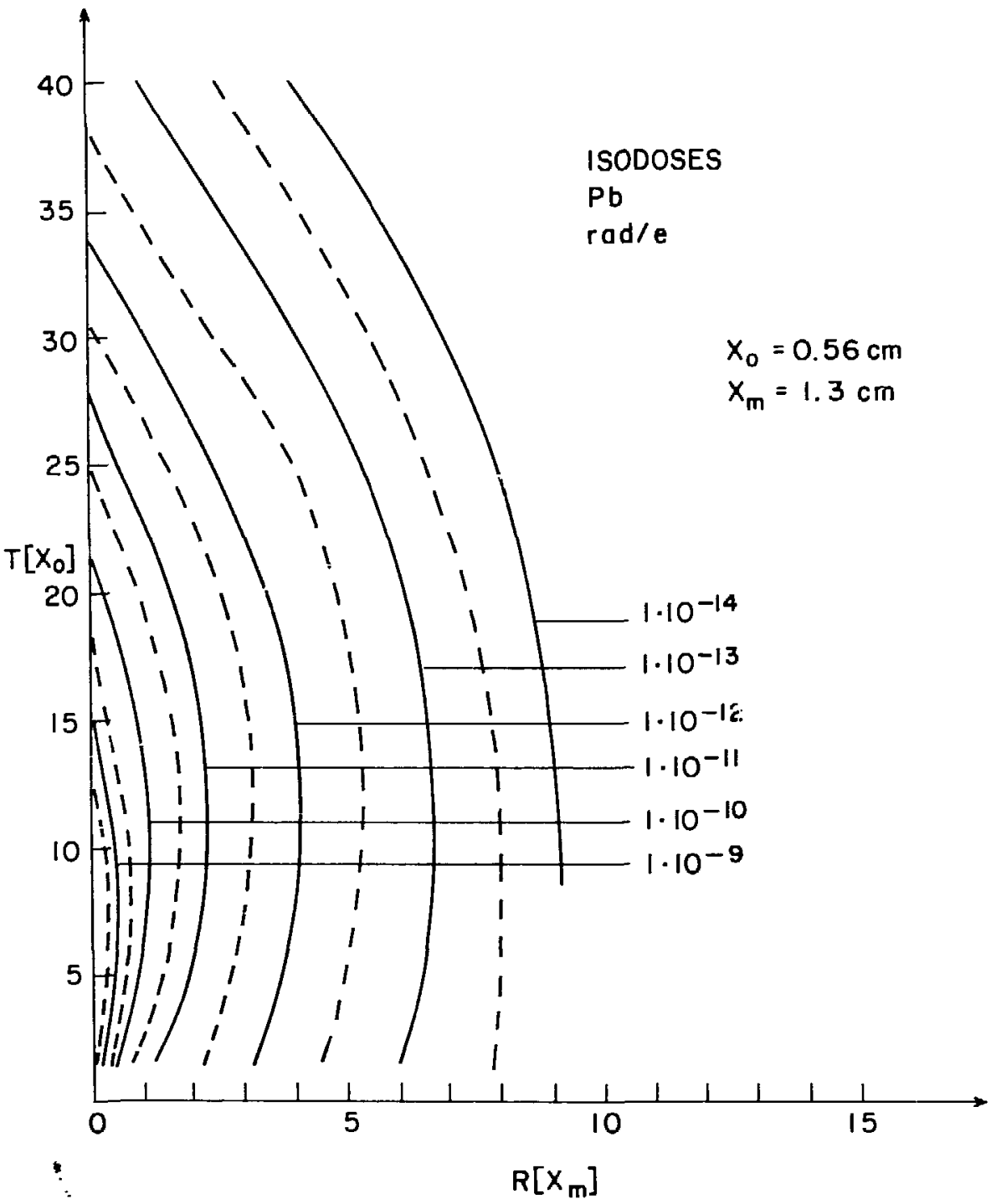

Figure D-3. Isadoses for lead. 
APFENDIX $V$ 


\section{Vistble Light Hazard at the NSLS VUV Ring.}

It is usually important, particularly in the VUV ring, to line up sptical components and check their focusing by using the visible portion of the synchrotron radiation spectrum. To do this, light is brought through a pyrex or kodial window which transmits wavelengths from 320 to $2700 \mathrm{~nm}$. We now calculate the hazard which this represents, and do so along the guidelines published by the "American Conference on Government and Industrial Hygiene" in their (1981) Threshold Limited Value (TLV) document. According to the ACGIH publication, our spectral range should be con-

sidered in three regions. (1) Near ultra-violtet (320-400 nm),

visible and near infrared $(400-770 \mathrm{~nm})$ divided into (a) retinal thermal damage and (b) retinal photochemical damage and (c) infrared radiation ( $>770$ $\mathrm{nm})$.

1) Near ultra-violet (320-400 nm) ACGIH, p. 84

The recomended TLV for this spectrl region is $1 \mathrm{~m} \mathrm{~W} / \mathrm{cm}^{2}$ for periods less than 16 minutes. The exposure should not be greater than $1 \mathrm{~J} / \mathrm{cm}^{2}$ for periods less than 16 min'ites. For the NSLS source with 1 ampere circulating, $7.10^{12}$ photon/sec./.1\% bandpass $\frac{\Delta E}{E}$ are emitted per horizontal milliradian at $320 \mathrm{~nm}$. Ech photon carries an energy of 3.9 electron volts, thus the total power in the region $320-400 \mathrm{~nm}$.

$$
\begin{aligned}
& =7.10^{12} 3.8 \frac{800}{3.2} \mathrm{eV} / \text { second } \\
& =6.810^{15} \mathrm{eV} / \text { second }
\end{aligned}
$$


Since $1 \mathrm{eV}=1.6 \times 10^{-19}$ joules

$$
=1.110^{-3} \text { joules } / \text { second }
$$

This radiation illuminates as area of $2 \mathrm{~cm} \times .2 \mathrm{~cm}$ at the distance of closest approach, with is 2 meters. (The opening angles are 10 mradians vertically by 1 mradian horizontally.)

Thus the power density

$$
=2.75 \times 10^{-3} \text { joules } / \mathrm{cm}^{2} / \mathrm{sec} \text {. }
$$

Thus the maximum allowable exposure time

$$
=6 \text { minutes }
$$

(2) Visible and near infrared

(a) The requirements are that the spectal radiance of the source should not exceed

$$
\begin{aligned}
\sum_{400}^{1400} \quad \mathrm{~L}_{\lambda} \mathrm{R}_{\lambda} \Delta \lambda & =\frac{3 \cdot 10^{-3}}{10^{-5} \cdot 1.02} \\
& =1.5 \cdot 10^{5} \mathrm{~W} \mathrm{~cm}^{-2} \mathrm{Sr}^{-1}
\end{aligned}
$$

In the worst case the angular subtense of the source (at 2 meters) is $(1 / 2000)$ radians. Since the only direct exposure to the light will be accidental, we assume an exposure time equal to the blink response of 250 msecs.

Thus $\quad \frac{1}{\mathrm{dt}^{1 / 2}}=\frac{2000}{(.25)^{1 / 2}}$

Thus we see that the light source operating at $1000 \mathrm{~mA}$ exceeds the TLV guidelines by

$$
\begin{aligned}
& =\frac{1 \cdot 5 \cdot 10^{5}}{4 \cdot 10^{3}} \\
& =38 \text { times }
\end{aligned}
$$


(b) Retinal photochemical injury

The guidelines require

$$
\sum_{400}^{1400} \mathrm{~L}_{\lambda} \mathrm{tB}_{\lambda} \Delta \lambda \leq 100 \mathrm{~J} \mathrm{~cm}^{-2} \mathrm{Sr}^{-1} \text { (for } \mathrm{t}<10^{4} \mathrm{~s} \text { ) }
$$

where $B_{\lambda}$ varies between .001 and 1 .

If we assume $B=.1$ and the total power is 3 mwatts, we have from before that

$$
\sum_{400}^{1400} \mathrm{~L}_{\lambda} \mathrm{tB} \lambda^{\Delta \lambda}=3.810^{3} \mathrm{~J} \mathrm{~cm}^{-2} \mathrm{Sr}^{-1}
$$

$=38$ times

(3) Inf rared Radiation

For radiation $>770 \mathrm{~nm}$ we always have a power density of less than 10 $\mathrm{mw} / \mathrm{cm}^{2}$ which is the TLV guideline.

Recommendations

At stored beam currents of greater than 26 milliamps we exceed the TLV guidelines for retinal burn and photochemical damage. To keep within the guidelines filters of no greater than $3 \%$ (broadband) transmission would be required at currents up to 1000 milliamps. These would be required at any window capable of transmitting the direct or specularly reflected beam. The alternative to this would be administrative control. 
APPENDIX VI

GUIDELINES FOR BEAMLINE RADIATION SAFETY

NATIONAL SYNCHROTRON LIGHT SOURCE

June 1981

$-103-$ 
In order to operate the experimental facilities safely, it is necessary to provide certain administrative controls. The success of the operation depends on the conscientious cooperation by all visitors and staff members. Any intentional violation of these procedures will be considered to be very serious and will be dealt with at the Laboratory Director's level. It may lead to a termination of the privilege of using NSLS facilities.

Prior to the final allocation of beam time on the NSLS facility, every experimental group will be required to submit a description including drawings of their experimental equipment to the Project Safety Committee for review. The exact form of this information and the type of information will be determined by that Committee with input from the user groups. 


\section{INTRODUCTION}

This report will cover means of assuring safe access to various beam line components by protecting experimenters and maintenance persons from radiatiol that originates in or near the storage ring and which is confined to inside the experimental beam ports. As can be seen in Figure 1 , the $\mathrm{X}$-ray storage ring is shielded from the experimental floor by a concrete tunnel. The wU ring will be shielded by an g-ia con: $\cdots+2 . \cdots i$ if necessary. Both rings have lead shielding in the median plane. For purposes of simplification, we will assume that hazardous radiation from all sources external to the beam tubes will be attenuated by passive shielding. In practice, radiation levels will be carefully monitored and local shielding upgraded as required.

Operating conditions at the experimental beam lines will be separated into the three following classifications:

\section{CLASS A}

This extremely hazaardous condition exists when the radiation is on a direct line-of-sight into the storage ring. Blumberg and Perlnan have calculated the maximum credible accident associated with beam line radiacion safety which follows a vacuum failure. The resulting interaction between the inrushing alr and the electron beam produces a life-threatening level of bremsstrahlung to an experimenter in the line of sight.

\section{CLASS B}

This classification implies that serious injury is possible to limited portions of the body from relatively short exposures of monochromatized

\footnotetext{
TMaximum Credible Accident, Memorandum by L. Blumberg and 14 . Perlman, May 6,1980 .
} 


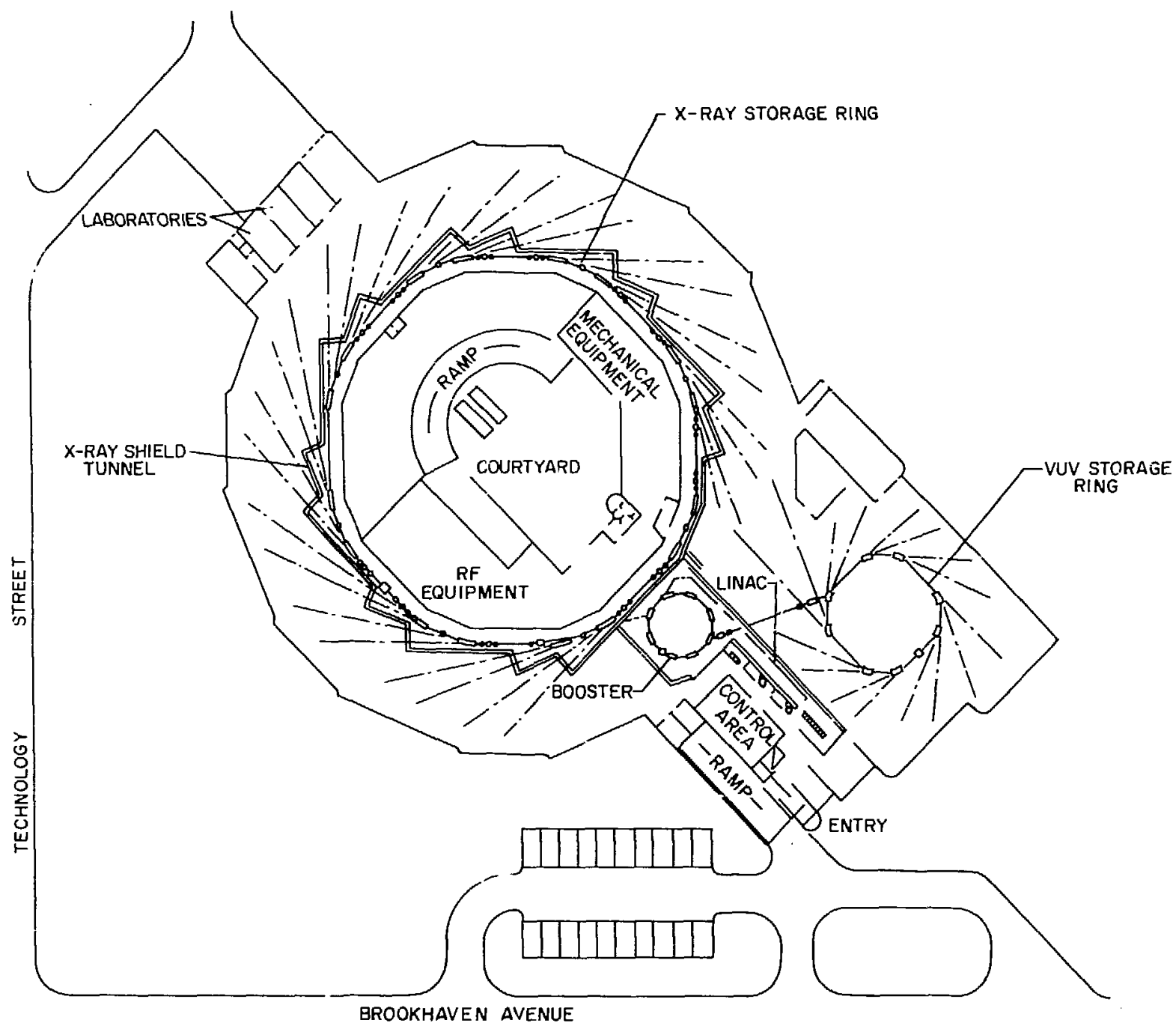

Figure F-1. Building layout of the NSLS. 
photons in the X-ray experimental beam line. It is assumed that line-ofsight radiation is properly shielded from both bremsstrahlung and syachrotron radiation.

\section{CLASS C}

Two types of radiation fall into this category. The first is synchrotronradiation from the VUV ring which has gone through a deflection in a mirror box or monochromator and is shielded from a line of sight to the storage ring. The second is monochromatized X-ray photons which have passed through an attenuator to degrade the flux by several orders of magnitude. The VUV photons are very hazardous to the eyes, efther from direct view or from a specularly reflected beam. There is no short term injury to the rest of the body. Monochromatized X-ray photons can be attenuated to a level to correspond in hazard to a source from a $1 \mathrm{kV} \mathrm{X}$-ray tube.

\section{X-RAY BEAM LINE}

$2.1 \mathrm{X}$-ray beam line coniponents are shown schematical1y in Figure 2. The front end is comprised of a photon mask, UHV and fast valves, beam splitter, beam-defining slit mechanisms and a safety shutter for each branch line. All front end components are located within a "sawtooth" concrete shield and are remotely operable since they are not accessible during storage ring operation. Sensors on the mask, UHV valve and safety shutter indicate open and closed positions.

The photon mask protects the UHV valve from overheating when the valve is closed. Since the $\mathrm{X}$-ray beam may be split into two or more branches, it is important that safety shutters operate independently. Therefore, a water-cooled photon mask is incorporated into the upstream end of each safety 


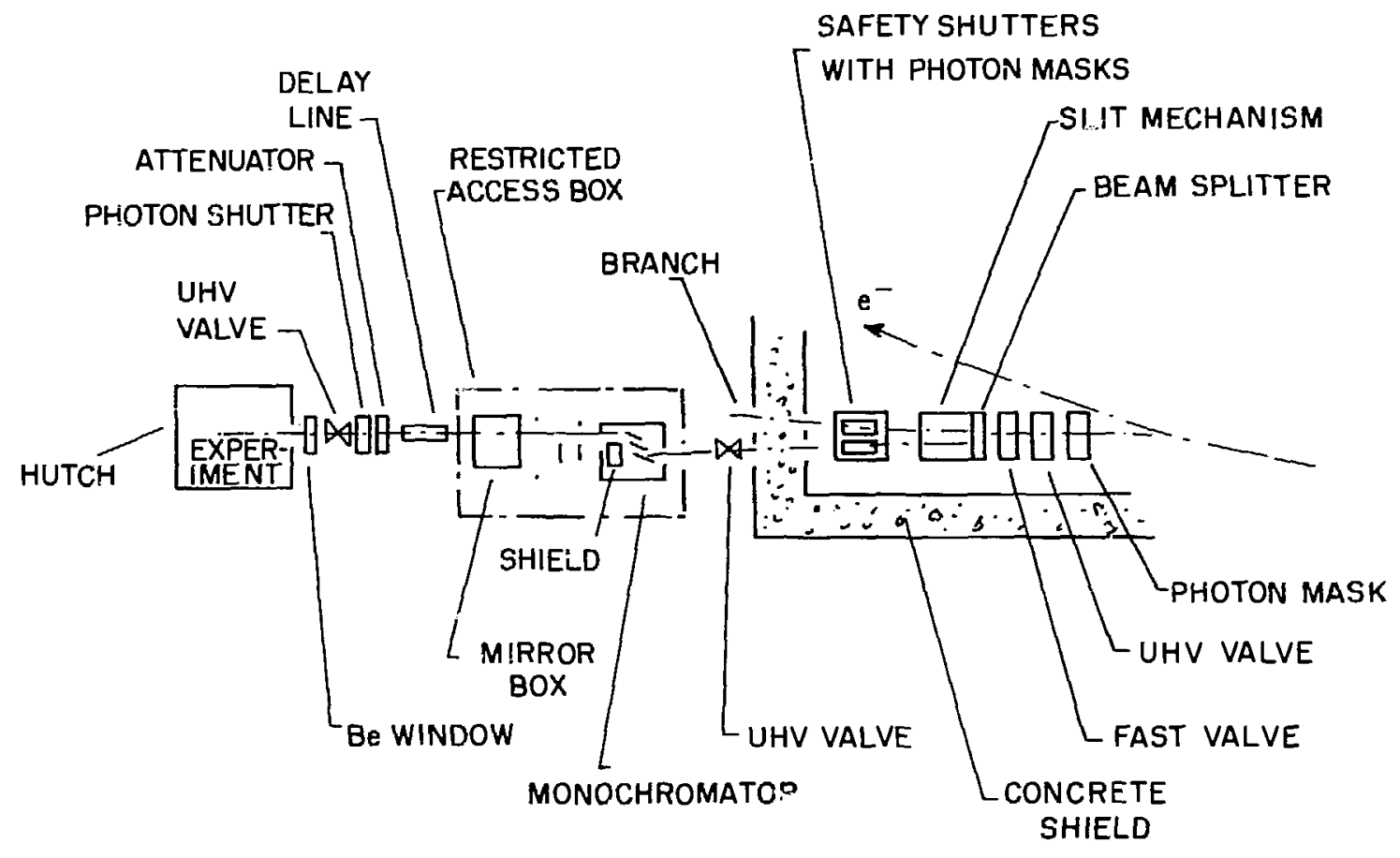

Figure F-2. Typical x-ray beamline. 
shutter to thermally protect it from the synchrotron radiation. ${ }^{1}$ Thus, it is possible to close one safety shutter in order to work on downstream componenis while the photon beam in the adjoining branch is in use.

The beam transport between the front end and the optical elements will be a sealed vacuum tube having a UHV isolating valve. A lead shield ( 1.5 to $2 \mathrm{~mm}$ ) will be placed around the tube to intercept stray photons. For some experiments, a beam-defining slit assembly will be located in the beam transport.

Figure 2 shows the two-crystal, fixed exit beam monochromator and mirror box that comprise the optical elements. Some geometries could have more than one mirror box. Some current designs call for helium-compatible optics, others require UHV or low vacuum environments. For the present design, vacuum isolation will be placed upstream of the monochromator or nirror box (in the two mirror box array) in the bean transport.

It is important that thermal transfents on mirrors and monochromator crystals be minimized during the course of an experiment. This may require that all front end components remain open during normal operation so that the impingement of the photon beam on optical elements will not be interrupted. The mirror box and monochromator, along with their vacuum hardware, are either located within an enclosure or the mirro: box and monochromator housings serve as the enclosure. Access to this enclosure is possible only when the safety shuter is closed.

In Figure 2, the beam transport between the optical elements and the experiments contains a delay line, photon mask, and a UHV valve. In addition,

\footnotetext{
Thermal design of $X$-ray components is covered in report entitled "Analysis of Thermal Problems of X-ray Beam Lines, Part I", W. Thomlinson and $\mathrm{K}$. Ludwig, BNL 26420, July, 1979.
} 
some lines will have an attenuator and beryllium windows. The delay line and other vacuum protection devices are described elsewhere. 1 The purpose of the attenuator is to reduce the monochromatized photon intensity. The photon shutter in the beam transport must be closed prior to 'whole-body' access to a hutch on a monochronatic beam line. A hutch is an enclosure around experimental equipment that may be large enough for personnel access. The experimental area within the hutch contains various equipment to mount and manipulate samples in suitable environments and detectors for data collection. A hutch provides restricted access to this instrumentation and provides beam stops and other shielding as required.

Each beam line w11 have a control and information station which will display, in addition to storage ring status, the positions of monochromator eiements, mirrors and slits. Also displayed will be the status of the safety shutter, attenuator and photon mask and photon shutter. This station will contain Kirk keys, unique only to a specific beam line branch, which will provide access to the hutch and monochromator-mirror box enclosure when safety conditions are satisfied.

\subsection{X-ray Beam Line Safety Prilosophy}

The approach to beam line safety for Class A and Class B applications (see Introduction) is to provide components that are fail safe to the furthest extent practicable and to have a redundant back-up system in the event of the failure of the primary safety element.

Safety shutters, the photon mask and the shutter are operated by means of pneumatic cylinders and are designed so that the beam stopping

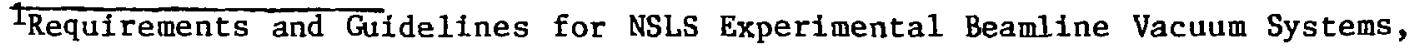
J. B. Godel and J. C. Schuchman, BNL Informal Report 28073, July, 1980.
} 
elements will be inserted into the beam in the event of an air stoppage.

Redundant electrically interlocked, position indication switches are provided for each comporent.

It is possible for Individual beam lines to be 'locked out' of service either from the control rom or the experimental station by lowering the shutter. In the locked out mode, the shutter cannot be raised independently from efther the experimental station or control room.

\subsubsection{Class A Protection}

a. When working on the monochromator or the beam transport, exposure to line-of-sight bremsstrahlung can occur. Routine adjustments to the monochromator and mirror box will be made remotely, without entering the restricted access box. Normalıy, this enclosure will not be large enough so that a person can be inside and hidden from view. Opening the box is by means of a Kirk key, available only after the safety shutter is closed. Returning a monochromator to service after it has been opened requires an inspection by a 'safety person' to verify that passive shielding is in place.

b. Non-routine installation of beam line components require that the safety shutter be closed.

c. Protection during initial beam line installation is achieved either by padlocking the safety shutter in its closed position or by locking out the shutter from the control room.

d. Work on front ends within the shielded area can only take place when the storage ring is not operating. Access doors must be interlocked to prevent startup if they are not in 
place. This area, along with the X-ray tunnel, will be inspected for occupancy before startup.

e. White beam experiments, i.e., where unmonochromatized photons are transported to the hutch, will require a shielded enclosure around the beam transport pipe, and may require a specially shielded hutch. A lead beam stop will be required in the hutch. Entry into the hutch is not possible without first closing the safety shutter.

\subsubsection{Class B Protection}

a. Exposure to photons while servicing the mirror box following a monochromator is prevented by a Kirk key interlock which prevents the restricted access box from being opened without first closing the safety shutter and its integral photon mask.

b. A door in the hutch will not open unless the photon shutter between the hutch and mirror box is shut. With the photon shutter down, it will be possible to enter the hutch except for white beam experiments as discussed in 2.2.1e, above.

\subsection{Class C Protection}

We have defined this condition as one where monochromatized $\mathrm{X}$-rays are attenuated to a level corresponding to a laboratory $\mathrm{X}$-ray source. Inserting the attenuator into the beam activates the interlock that permits the hutch door to be opened for the case of attenuated beam hutch access (paragaraph 2.3.3). This 
mode of operation will be allowed for experiments where the scientific necessity is demonstrated to the NSLS Safety Committee. In general, attenuated beam access will be discouraged.

a. It is expected that some experimenters will require openings in the hutch just large enough to insert a hand or arm. However, others will require full access to the hutch. Thomlinson ${ }^{1}$ has calculated the maximum dose from an accidental exposure to an attenuated beam. It is comparable to that from a $1 \mathrm{kN}$ laboratory $\mathrm{X}$-ray generating tube.

b. A:cess to the hutch with the attenuator inserted will conform to BNL's "Occupational Health and Safety Guide for Analytical X-ray Facilities," Section 3.4.2, and NBS Handbook 111, "Radiation s sfety for X-ray Diffraction and Fluorescence Analysis Equipment."

\subsection{X-ray Safety Logic}

2.3.1 'Whole Body' Access to Hutch (Safety Shutter Open Monochromatic Beam)

a. Experimenter pushes 'photon shutter closed' button.

b. Photon shutter closed is indicated at Experimental Station and Control Room.

c. Positive closure of photon shutter releases kirk key.

TRadiation Intensity of Attenuated Beam Operation for NSLS X-ray Beamlines, Menorandum by $\mathrm{W}$. Thomlinson, August 25, 1980 . 
d. Key unlocks hutch door and the key is captured by the lock. Unlocking the door with a photon beam present in the hutch dumps the electron beam.

e. To return the experiment to the 'beam-on' condition, the experimenter enters the hutch. Inspection stations inside the hutch must be activated sequentially. These stations are so arranged that the experimenter is forced to search the hutch for occupants.

f. After activating the final station the experimenter has a predetermined length of time (typically 15 seconds) to isave the hutch and close the door. Failure to close the door in the specified time will prevent the shutter from opening and the search procedure must be repeated. If the door is opened after the search, the search procedure must be repeated before the shutter can be opened.

g. The door is then locked, releasing the key. The Kirk key can then be used to open the shutter and return the line to operation.

$h$. When the shutter 'open' command is given, there is a 30 second delay while both an audible and a visible alarm are operated inside the hutch. An emergency beam dump controi will be in each hutch.

i. Pressure sensitive mats will cover the open areas of the floor of each hutch. A load about 70 lbs or greater on any mat will prevent the shutter from opening. 
j. With the shutter oper, a load of $70 \mathrm{lbs}$. or more on the mats will cause a ring electron beam dump.

\subsection{2 'Whole Body' Access to Hutch (White Beam)}

The safety logic for this mode is identical to Section 2.3.1 except that it is the satety shutter which is operated and not the photon shutter.

\subsection{3 'Whole Body' Access to Hutch (Attenuated Beam)}

a. Experimenter asks Control Room for key to operate in attenuated mode.

b. Removal of key from Control Room closes the attenuator.

c. Insertion of Control Room key into attenuator releases hutch key if attenuator is closed.

d. Hutch key opens door and is captured in hutch door.

e. The open hutch door activates an interlock which prevents inadvertent entry. This interlock must be bypassed by positive action each time entry or egress is desired. Failure to do so will cause the photon shutter to be inserted.

f. A hutch warning light is activated when the attenuator is inserted.

g. Experimental equipment in hutch will have fail-safe manual shutters so that the beam can be turned off at times when it is not required.

There shall be guards or interlocks to prevent entry of the body into the primary beam path. 
h. To return to full beam-on operation, the experimenter must first close the photon shutter, then inspect the hutch for occupants, activate the inspection station interlock, close the hutch door and return the door key to the attenuator control station in order to telease Control Room key. The Control Room key is then returned to the Control Room where it is used to remove the attenuator from the photon beam.

\subsection{4 'Arm Only" Access to Hutch (Photon or Safety Shutter Closed)}

a. Experimenter can close safety or photon shutter. Positive, closed indication of either will release two Kirk-type keys. One of these keys will open hutch for whole body access. The procedure for access will follow Section 2.3.1 or 2.3.4. The other key will open the hutch in such a way that orily arm access is possible.

b. To return to beam-on from 'arm only' access mode, experimenter removes key from door and uses it to release control of the shutter. Inspection station sequence is not required.

2.3.5 Access to Interiors of Monochromator and Mirror Box

a. Experimenter pushes 'safety shutter closed' control.

b. Positive indication of closed shutter releases appropriate Kirk key.

c. Kirk key opens enclosure door and is captured in door.

d. Entering monochromator or mirror box may require disabling vacuum interlocks. This subject is covered elsewhere. 


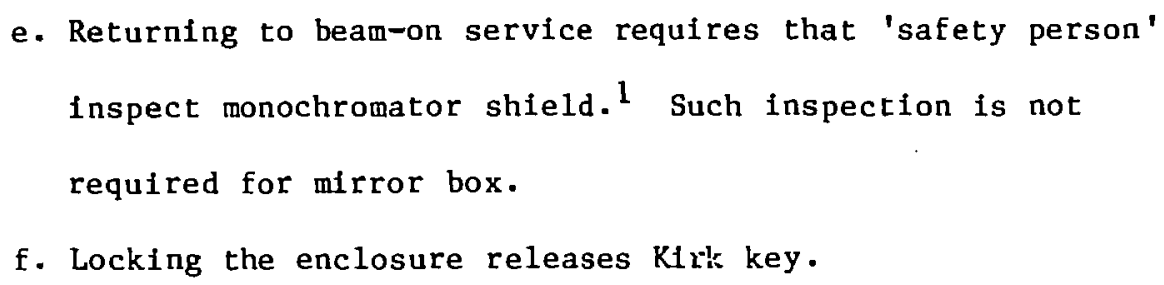

3. VUV BEAM LINES

\subsection{VUV Beam Line Description}

VUV beam line components are shown schematically in Figure 3 . The front sad comprises a photon mask, a UHV and a fast valve and a safety shutter. The safety shutter will be closed during electron beam injection. The front end is followed by the first mirror box, the monochromator, a second mirror box and an experimental chamber. On some beam lines some of these components may not be present, in other beam lines, there may be further duplication of components. Usually, the components will be in a vacuum enclosure.

The safety shutter a:d valves at the front end are protected from overheating by the water-cooled mask. When the safety shutter is closed there is no direct line-of-sight exposure to the ring. The front end components are mounted on a table with the required concrete shielding.

The safety shutter is designed to absorb the bremsstrahlung produced during electron beam injection or in the event of an accident such as described in the Introduction.

\subsection{Safety Philosophy}

There is the possibility that a beam dump occurs due to gas entering the storage ring from a beam line. This produces a line-of-sight condition

\footnotetext{
This is the lead shield that prevents line-of-sight from storage ring to components downstream of monochromator.
} 


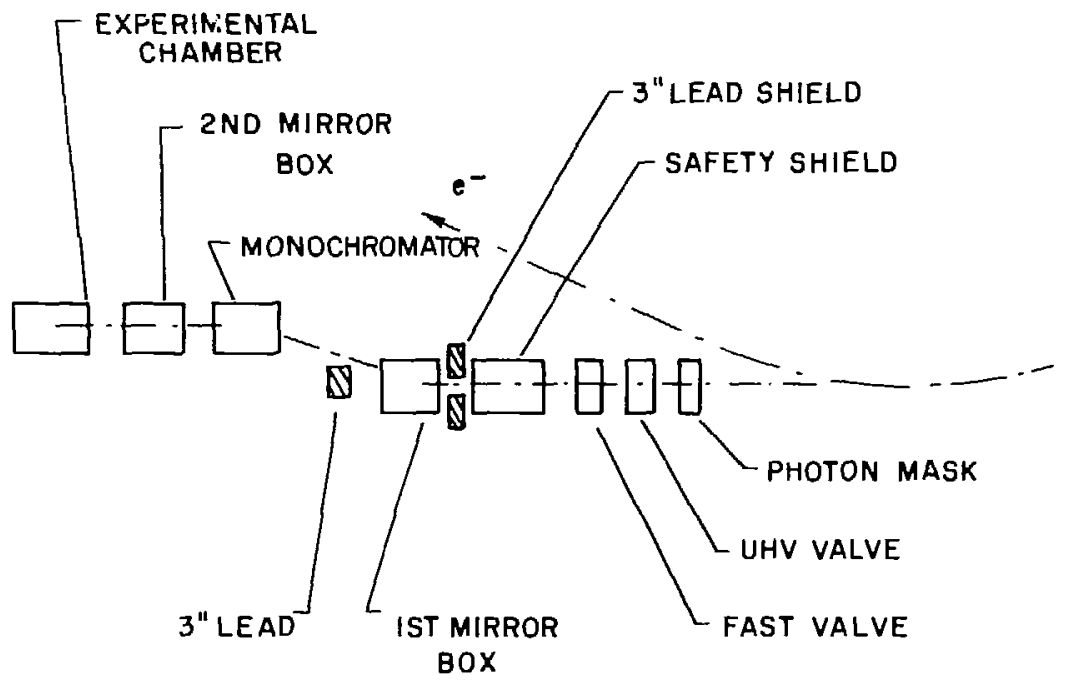

Figure F-3. Typical VUV beamline. 
which is a Class A hazard. Three inches of lead are required to provide shielding to protect personnel from this risk. Another hazard is to the eyes from the visible part of the spectrum. To get out to air, the radiation must pass tı.rough a window; pyrex glass windows will eliminate all other wavelengths but those in the visible region. The total power of the synchrotron radiation from a $700 \mathrm{MeV}$ one ampere beam in the visible region is of the order of $10^{-3}$ watts per milliradian horizontally but the vertical divergence is greater than that of a laser. ${ }^{1}$ For safety reasons we will conservatively consider it equivalent to a Class $\mathrm{II}^{2}$ laser.

All geometric lines tangential to the electron orbit will be blocked by 3 inches of fixed lead shielding or equivalent. For beam lines this will be provided after the first deflection. See Figure 3. The bean line vacuum envelope itself will prevent interception of the beam by experimenters prior to this deflection. If a white (and undeflected) beam is required or if this lead cannot be provided as shown in Figure 3 because of inadequate deflection, then this will be terminated by a hutch, access to which will be the same as For an X-ray white beam.

Following the guidelines for Class II lasers, all viewports capable of transmitting the direct or reflected visible portion of the beam shall normally be covered and the cover shall bear the warning: CAUTION - INTENSE SYNCHROTRON LIGHT BEAM, DO NOT STARE INTO BEAM. In the event that the beam is required in the room, the area traversed by the beam is to be roped off preventing inadvertent access and backstopped within the roped off area. A notice CAUTION - DO NOT STARE INTO SYNCHROTRON LIGHT BEAM is to be placed in a

\footnotetext{
TMemorandum, Visible Light Hazard at the NSLS VUV Ring, G. P. Williams, May $23,1980$.

20ccupational Health and Safety Guide, Lasers, Section 2.3.1, April 5, 1976, Brookhaven National Laboratory.
} 
conspicuous location. If a beam is required only temporarily to check alignment and the person removing the window cover prevents access to the beam by others, no additional precautions are required. the "CAUTION" warning notices will be provided by NSLS.

\subsection{Setting Up a VUV Beam Line}

This is defined as operating in line-of-sight with the safety shutter open under circumstances when the above requirements of lead shielding are not fulfilled. A vacuum accident with resulting bremsstrahlung as described above could result in a Class A hazard for one amp beam operation. Therefore, operation during setup of a VUV beam line will be permitted only with reduced electron beam. A beam current of 10 milliamps is expected to give a dose of about 35 rads in the event of an accident. It is possible to set up an experiment at currents less than 10 milliamps.

\subsection{Safety Logic}

3.4.1 Safety shutters can be closed and locked out from the Control Room.

3.4.2 Under normal operating conditions, control of the safety shutters will be the responsibility of the experimenter, except for a white beam experiment. See Section 2.3.2.

4. ADMINISTRATIVE CONTROLS, X-RAY AND VUV EXPERIMENTAL AREAS

4.1 The experimental areas at the NSLS will have controlled access. Entry will be allowed only to persons with authorized personal radiation monitors and entry key. In order to obtain the monitors and keys, a safety training session must be attended at which a NSLS safety officer will descrite all hazards and pzoper operating procedures. The responsibilities of the 
individuals with regard to the safe utilization of the facility and the penalties for failure to do so will be made clear.

4.2 Anyone who will operate the beam line safety controls will be given additional training.

4.3 For each beam line, a line of responsibility for safety will be established fcr any group operating a beam line. It will be the responsibility of each person to assure the safe operation of beam lines by those individuals assigned to it.

4.4 Short term visits to the experimental floor may be allowed if an approved sign-in procedure is followed and the visitor is accompanied by a person who has completed the safety training. Longer term visits (e.g. a workman repairing cabling or plumbing) will be allowed if the sign-in procedure is followed and the individuals are under the supervision of a trained person.

4.5 The NSLS operators will have the option of interceding at any time in the operation of beam line shutters. They will close the shutters if an unsafe condition is deemed to exist, and they will block the opening of the shutters for safety reasons as well.

4.6 The operators on each shift will have the responsibility for the safe operation of the experfmental fcilities. Questions regarding beam line operation safety will be directed to the operator. He will have the responsibility of checking hutches and beam lines and will enforce all safety rules. Random checks of experiments wi:-1 be made.

4.7 When an experiment is greatly modified or a new group of users begin using a beam line, a safety check will be made to insure adequate experimental safeguards, and to insure that each person working on the project understands the operation of the shutters. Only then will the shutters be allowed to be operated by the experimenters. 